\title{
RUTAS Y SENDEROS PREHISPÁNICOS COMO PAISAJES. LAS QUEBRADAS ALTAS DEL VALLE CALCHAQUÍ MEDIO (SALTA)
}

\author{
PREHISPANIC PATHS AND TRAILS AS LANDSCAPES. THE HIGH \\ QUEBRADAS OF THE MID CALCHAQUI VALLEY (SALTA)
}

Verónica Williams ${ }^{A}$ \& Paula Villegas ${ }^{B}$

En las quebradas altas del valle Calchaquí medio, en la Provincia de Salta, se ha reconocido una serie de sitios Incas y tramos de caminería imperial, llevándonos a postular la importancia de las comunicaciones transversales entre los valles mesotermales y el ambiente puneño en este sector del Tawantinsuyu. Planteamos algunas posibilidades de comunicación entre distintas unidades geoambientales a partir del registro arqueológico e información histórica de los siglos XVI, XVII y XVIII.

Palabras clave: paisaje, Camino Inca, Qhapaq Nan, valle Calchaquí, Salta.

In the high ravines of the mid Calchaqui valley, Salta province, we have found a series of Inca sites and roads that led us to postulate the importance of transversal communications between mesothermal valleys and Puna environment in this area of the Tawantinsuyu. Based on the archaeological record and historical information from the $16^{\text {th }}, 17^{\text {th }}$ and $18^{\text {th }}$ centuries, we discuss the possibilities of communication between different geographic and environmental units.

Keywords: landscape, Inca Road, Qhapaq Nan, Calchaqui valley, Salta.

\section{INTRODUCCIÓN}

Los estudios de la colonización inca en los territorios del sur del Imperio, específicamente el Noroeste de Argentina (NOA), permanecen todavía tentativos a pesar de los avances realizados en los últimos 30 años, especialmente porque el conocimiento sobre la expansión del Estado Inca hacia los Andes del sur descansa más sobre modelos emanados de la etnohistoria que sobre la contrastación y explicación de datos arqueológicos. El énfasis de los análisis históricos radica en el funcionamiento de las estructuras políticas, económicas e ideológicas estatales a nivel de las élites dirigentes, relegando a un segundo plano otros segmentos de estas sociedades o los procesos sociales ocurridos en comunidades locales alejadas de los centros políticos principales. En los últimos años se ha insistido en la necesidad de desarrollar nuevas orientaciones y marcos teóricos alternativos derivados del análisis crítico de datos arqueológicos cuyos resultados muestran un panorama más dinámico y heterogéneo de los modos de interacción del Estado Inca con los territorios anexados.

El objetivo del trabajo es comprender la construcción de las particulares espacialidades incas en las quebradas

\footnotetext{
A Verónica Williams, Universidad de Buenos Aires, Facultad Filosofia y Letras - CONICET. Instituto de las Culturas (IDECU). Buenos Aires, Argentina, email: veronicaw33@yahoo.com

B M. Paula Villegas, Instituto de Arqueología, FFYL, UBA, 25 de mayo $2173^{\circ}$ piso, CABA, Argentina, email: paulavil78@yahoo.com.ar Recibido: diciembre 2015. Aceptado: marzo 2016.
} 
altas de Gualfín, Tacuil y Luracatao en el sector medio del valle Calchaquí, en la provincia de Salta, Argentina, donde la red vial es uno de los marcadores de la presencia estatal, constituyendo en sí misma un complejo sistema administrativo, de comunicación y transporte (fig. 1). Si bien muchos de los tramos son en parte mejoramientos sobre vías de comunicación previas, la red caminera asociada a sitios estatales formó la infraestructura del control inca en las provincias (Malpass 1993: 240).

Los caminos constituyeron un símbolo omnipresente del poder y la autoridad del Estado, $y$ fueron fundamentales a la hora de integrar y mantener el funcionamiento de un territorio tan extenso. En este sentido, funcionaron a su vez como bisagra en la unión de dos paisajes, el local y el estatal (Hyslop 1984: 2), siendo al mismo tiempo un marcador espacial en la territorialidad simbólica estatal, como propone Berenguer (2001).

En el NOA, el estudio de caminos está íntimamente relacionado con aquel de los sitios de filiación Inca (Raffino 1981; Hyslop 1984; Vitry 2000, 2004; Bárcena 2005; Moralejo 2011, entre otros). Aquí seguimos el criterio propuesto por Hyslop (1984: 3), quien considera como Camino Inca toda ruta que exhibe o no elementos formales de construcción, usada en momentos imperiales y a la cual están asociados asentamientos cuya función se vincula con la administración del Estado.

Utilizamos datos provenientes del cruce de fuentes documentales y el registro arqueológico. Para el primer caso, destacamos el problema de la escasez de información documental temprana para la zona, razón por la cual incorporamos documentación del siglo xviII y cartografía e informes producidos por viajeros y naturalistas del siglo XIx. Para el segundo caso, disponemos de datos arqueológicos producidos a partir de estudios sobre uso y construcción del espacio, y sobre patrones arquitectónicos realizados en asentamientos de tipo pukara, sitios ubicados en cotas más bajas o poblados pequeños semiconglomerados, terrazas y andenes, arte rupestre, caminería, santuarios y ofrendatorios de altura.

La apropiación y el uso que las poblaciones hacen del medio en que habitan es uno de los principales factores que influyen en la configuración de sus patrones de asentamiento. Al considerar el espacio como una construcción social, el concepto de paisaje es entendido como la conjunción de rasgos naturales y artificiales y un tipo particular de racionalidad espacial, factible de ser modificada en el tiempo, cobra particular relevancia (Thomas 2001). La percepción, significación y cons- trucción de paisajes implican actos que recurren a la memoria relacionando sentidos, historias y experiencias de vida (Ingold 1993), memoria que estará anclada a una construcción vinculante de identificación cultural o pertenencia y a un territorio.

Entendemos por territorio, siguiendo la formulación de Raffestin (1986: 177), la apropiación social de un espacio mediante el agenciamiento de aquellos recursos económicos y simbólicos que estructuran las condiciones prácticas de la existencia de un colectivo autoidentificado con el mismo. Este concepto es indisociable del de territorialidad, en tanto que estructura relacional y multidimensional establecida entre una sociedad y su territorio, y que comprende la identidad con un espacio determinado, la exclusividad proclamada dentro de este y los modos de interacción establecidos con el medio. Territorio como geosímbolo, espacio simbólico conformado por una serie de lugares e itinerarios, pertenencia, asiento de la memoria, ligado a identidades colectivas (Bonnemaison 1992, 2005).

Las dominaciones inca y castellana reconfiguraron los territorios prehispánicos en muchas partes de los Andes (Presta 2013). Un dato que surge de los documentos históricos tardíos para el NOA es la explotación de recursos en distintos pisos y por diferentes grupos. Desde la etnohistoria, se ha planteado que las sociedades prehispánicas de Calchaquí con asientos en el valle troncal extendían también sus derechos sobre franjas transversales, lo que al mismo les permitía acceso a recursos complementarios en zonas más altas; o bien se ha señalado que aquellas que tenían sus asientos en las quebradas altas también disfrutaban de derechos en el fondo del valle principal, donde "otras veces solían hacerlo", según los relatos (Lorandi \& Boixadós 1987-1988). En el valle Calchaquí medio, en 1659, los gualfines tenían derecho a tierras en Angastaco, dado que allí bajaban a hacer sus sementeras. Pero también los sichas compartían terrenos en este oasis junto al río Calchaquí, convirtiendo a Angastaco probablemente en un territorio multiétnico (Relación Anónima AGI, Charcas 121, en Lorandi \& Boixadós 1987-1988: 317).

La circulación desde los valles hacia la puna y las yungas está ilustrada por datos históricos y etnográficos, aunque la arqueología también ha aportado información sobre los circuitos de circulación.

Desde Molinos y Angastaco, las vías de comunicación natural hacia el este son por el norte del Calchaquí y acceden a la quebrada del Toro a través del río Potrero 


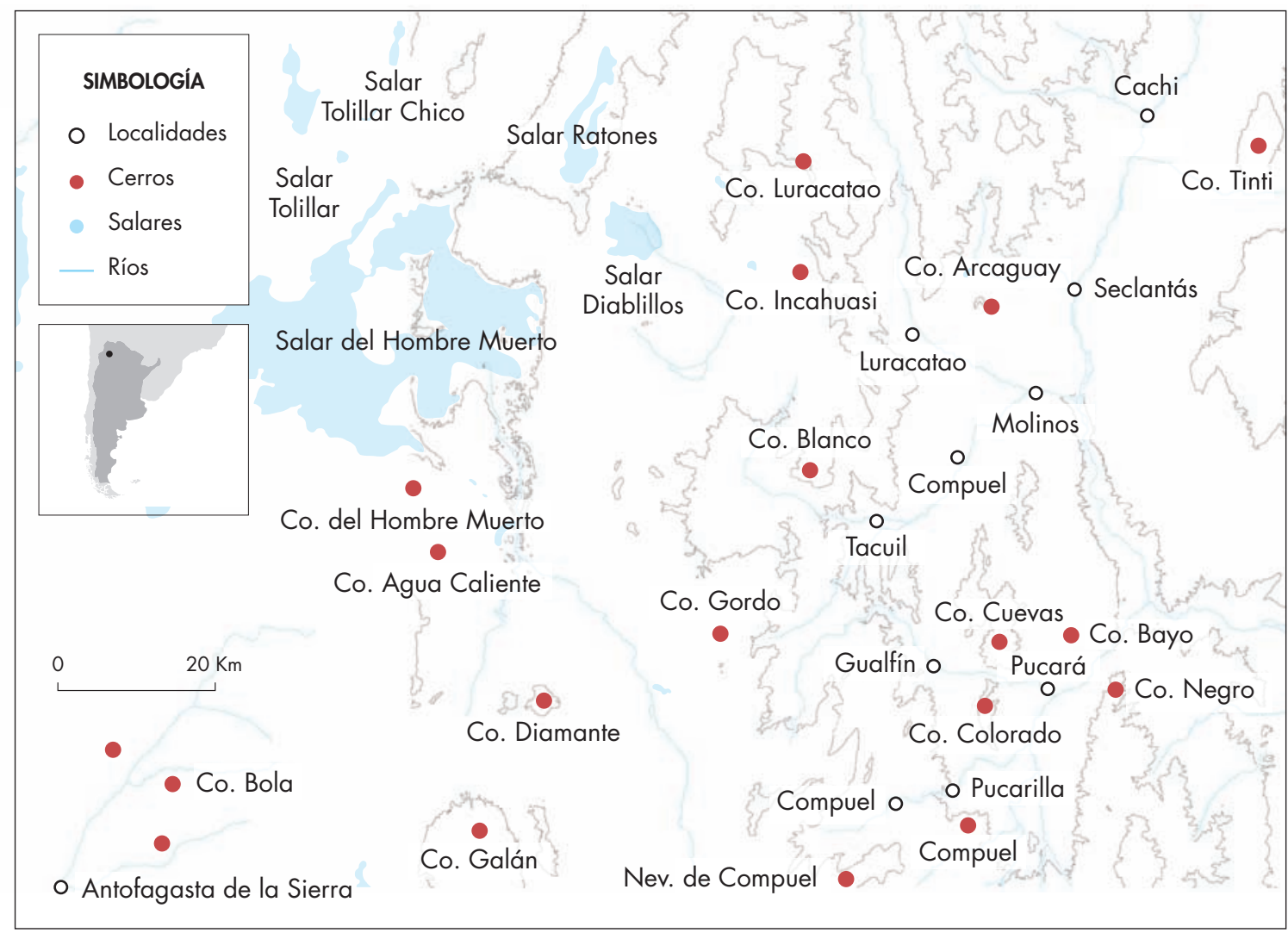

Figura 1. Área de estudio. Valle Calchaquí medio en la Provincia de Salta, Noroeste de Argentina. Figure 1. Area of analysis. Mid Calchaqui valley in the Province of Salta, Northwestern Argentina.

y por Payogasta, Tin Tin y la cuesta del Obispo, ruta de importante tránsito durante las primeras entradas (Larrouy 1923; Torreblanca 1999 [1696]). Al sur de Angastaco, un primer acceso factible se observa a la altura de Los Sauces, y el más meridional a través de la quebrada de Las Conchas (Sprovieri 2013).

Hacia fines del siglo XviII, los valles Calchaquíes se destacaban como área de invernada y tenían gran importancia como corredor de tránsito del ganado mular hacia Lima, Cuzco, Alto Perú y norte de Chile (Mata de López 2000). En el siglo xIx, los arrieros de Salta que llevaban tropillas a Copiapó solían pasar por Amaicha, Tacuil y Gualfín hasta empalmar con el camino que desde Santa María, en Catamarca, se dirige a Copiapó (Chile) (Strube Erdmann 1963). Para fines del siglo XIx y comienzos del xx, Benedetti (2005: 442) menciona las dos rutas más utilizadas para el comercio entre Salta y San Pedro de Atacama: la primera tomaba por la quebrada del Toro, Tastil, Chorrillos, Catúa, Hayquina, Soncor y
San Pedro de Atacama, y fue la seguida por Ambrosetti en 1905; la segunda ingresaba al territorio de los Andes desde Molinos, a través de Luracatao, siguiendo por Pastos Grandes y conectándose con la anterior, y fue el derrotero seguido por viajeros como Bertrand, Doering y Holmberg y Von Tschudi en 1860.

Esta movilidad y articulaciones económicas de larga distancia estuvieron respaldadas por relaciones de parentesco debido a la interdigitación que caracteriza a la población indígena de la puna y el desierto de Atacama durante el Período Colonial (sensu Martínez 1998). Precisamente, García et al. (2002) registraron vínculos de parentesco establecidos entre los habitantes de Antofagasta de la Sierra, en la puna catamarqueña, y los valles interserranos, entre ellos el Calchaquí. El área de Compuel era paso en el circuito que unía Antofagasta de la Sierra y Molinos/quebrada de Gualfín, siendo "la tercera o cuarta jornada en el camino a esos mismos valles" (García et al. 2002: 11). 
Desde la arqueología, señalamos en estas quebradas la existencia de asentamientos en zona altas (los pukara) y pequeños asentamientos diseminados en fondo de valle (Williams \& Villegas 2013). Pero hasta el momento no sabemos de qué tipo o naturaleza eran las relaciones entre estos núcleos residenciales, incluidos los pukara, y los que se encuentran en fondo de valle (como El Churcal, La Paya y Molinos 1 ó La Alumbrera y Coyparcito para la puna) o en la puna, más allá del hecho de que participaban de una cultura similar y de que ambos tenían acceso a tierras, pastos y caza en las zonas altas. Para el segundo milenio (Período Tardío/ Inca-Colonial), proponemos entonces que en las quebradas altas, alejadas de los grandes poblados de fondo de valle, habrían perdurado las autonomías locales, con una base familiar o comunitaria de toma de decisiones.

\section{VÍAS DE CIRCULACIÓN NATURALES EN EL VALLE CALCHAQUÍ MEDIO}

En el NOA, el río Calchaquí constituye una vía de circulación natural norte-sur de unos $200 \mathrm{~km}$ de distancia, desde sus nacientes en el nevado de Acay $(5.716 \mathrm{msnm})$ hasta su confluencia con el río Santa María ( $1.545 \mathrm{msnm}$ ). Fue una ruta privilegiada en las comunicaciones, funcionando como paso entre la Quebrada de Humahuaca; la puna de Salta y Catamarca y el valle de Santa María, posicionándose como un punto intermedio y de paso obligado en la circulación entre la puna occidental y las zonas bajas orientales (Tarragó 2000; Sprovieri 2013, entre otros).

En su sector medio, entre las actuales localidades de Seclantás y Angastaco, convergen dos ambientes morfológicos: puna y valles y quebradas. El área aquí trabajada está delimitada por la cuenca de Molinos al norte y Angastaco al sur y sus correspondientes tributarios, principales aportes de agua permanente en la zona (fig. 1). Estas quebradas altas habrían sido corredores naturales entre espacios con diferentes alturas, habitados por unidades de reproducción social autónomas y "puertas" hacia el paisaje puneño en donde se registran ofrendatorios y santuarios incas de altura, como el del cerro Incahuasi de Luracatao.

Sobre la base del análisis de mapas topográficos, fotografías aéreas e imágenes satelitales, observamos una serie de vías de circulación naturales y consideramos que, si bien las posibilidades son múltiples, debido a la topografía del área, el tránsito habría quedado limitado principalmente a los pasos de montaña (Villegas 2011, 2015). Mediante el uso de Sistemas de Información Geográfica (sIG) llevamos a cabo análisis de las cuencas visuales de los sitios de los diferentes momentos. Estos mapas nos brindaron información básica a partir de la cual generamos hipótesis tanto de los factores que pudieron influir en la localización de los sitios habitacionales como de las posibles relaciones espaciales y/o temporales entre ellos, con otros tipos de emplazamientos y con las vías de circulación. Este análisis resulta de particular utilidad debido a que las propiedades visuales pueden ser importantes a la hora de decidir dónde asentarse, por motivos tales como vigilancia y/o control (Fábrega \& Parcero 2007) o cuestiones estéticas, además de la información que aportan para estudios de percepción y simbolismo (García Sanjuán et al. 2006).

Hemos priorizado aquí las vías de comunicación más directas y de menor dificultad aparente, lo que no significa que hayan sido las efectivamente utilizadas por las poblaciones prehispánicas, ya que podrían haber circulado también por las cumbres o partes más altas (Lorandi \& de Hoyos 1995; Williams 2010) (fig. 2).

La teledetección permitió identificar al menos seis pasos posibles a la puna (Villegas 2015: 253):

1) Por la quebrada de Luracatao hacia el norte, desembocando en la puna salteña a la altura del Salar Centenario y Pastos Grandes, ruta utilizada como paso a Chile (von Tschudi 1967 [1858]; Philippi 1860; Bertrand 1885).

2) Partiendo de Tacuil, por el cauce del río de La Hoyada, a través del Abra del Cerro Blanco a través del río Barranquillas, accediendo a los salares de Diablillos, Ratones y del Hombre Muerto donde se localiza el sitio inca de Abra de Minas y la cueva Inca Viejo (Castillo 1978: 3; López \& Coloca 2015; López et al. 2015). Este paso fue utilizado en tiempos históricos (Strube Erdmann 1963).

3) También desde Tacuil, siguiendo el cauce del río Blanco, se llega al salar del Hombre Muerto a través del abra del cerro Gordo.

4) Hacia el sur, y siguiendo el río Mayuco, se ingresa a la puna al sur del cerro Gordo, llegando al valle del 


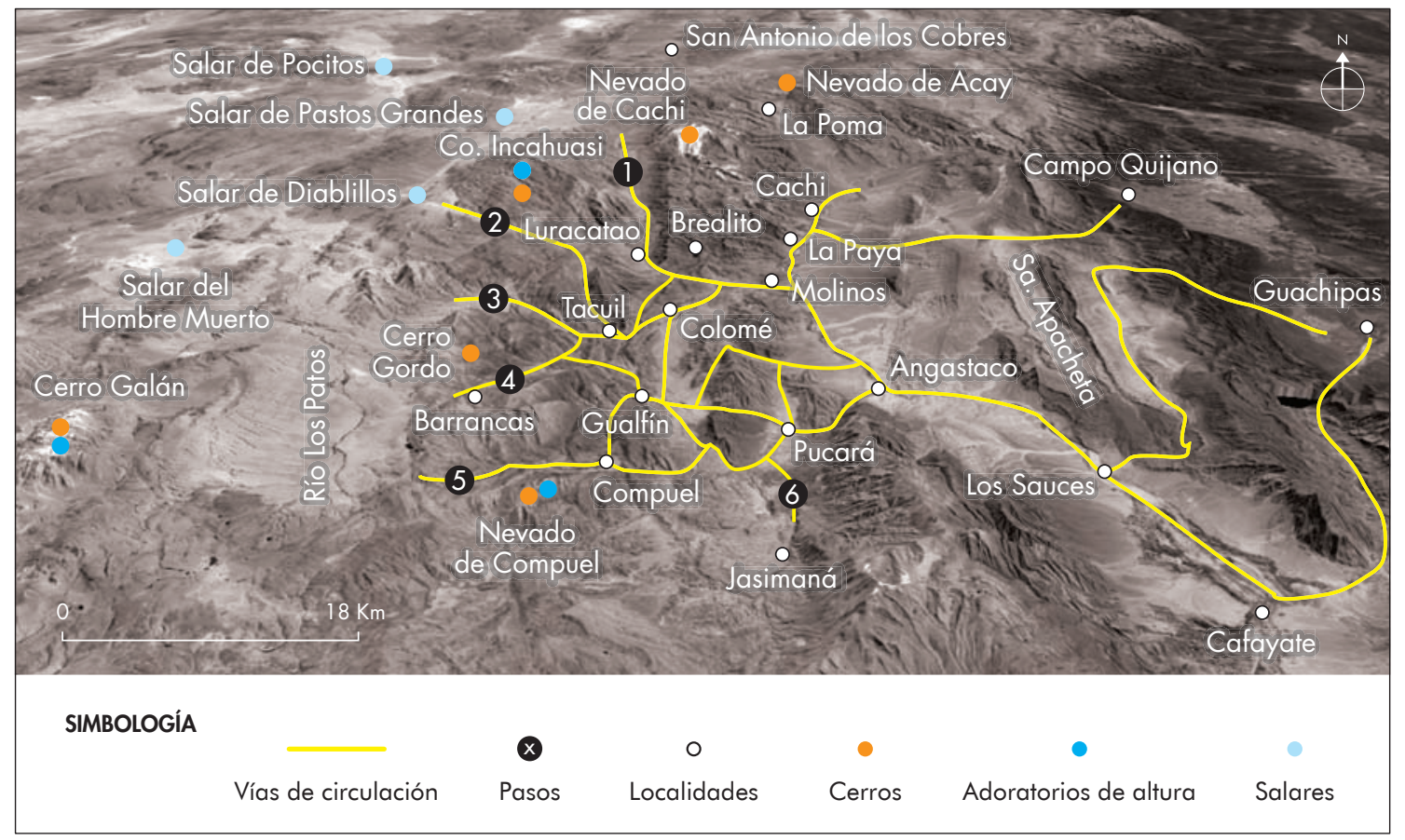

Figura 2. Vías de circulación naturales y principales accesos a la puna en el área de estudio (imagen Google Earth). Figure 2. Natural paths of circulation and main accesses to the Puna in the area under study (Google Earth image).

río Los Patos. Puede accederse a este paso también a través del cauce del río Gualfín (Bertrand 1885; Martel 2014).

5) Siguiendo el cauce del río Compuel y pasando entre el cerro Remate y el nevado de Compuel, se llega al río Los Patos y al cerro Galán. El uso de este paso está registrado históricamente (Levillier 1926; Olivera 1991; García et al. 2002).

6) Al sur de Pucará, por el cauce del río Guasamayo accediendo a Jasimaná y Pampa Llana. También se menciona que por esta ruta se puede alcanzar el valle del Cajón y de ahí el valle de Yocavil a través de Punta de Balasto, sitio inca en la actual provincia de Catamarca (Sprovieri 2013: 54).

La circulación desde los valles hacia la puna y las yungas y viceversa está ilustrada por datos históricos y etnográficos, aunque la arqueología también ha aportado información sobre los circuitos de circulación desde fines del siglo XviII.

\section{APORTES ARQUEOLÓGICOS A LOS CAMINOS}

La presencia de los pasos naturales que hemos señalado antes no implica necesariamente que los mismos hayan sido utilizados por las poblaciones prehispánicas en general, ni por el Imperio Inca en particular. Es por ello que presentaremos las evidencias arqueológicas registradas en el área y su relación con las vías de circulación naturales, a fin de comprender cómo pudo haber sido el movimiento de personas, objetos y materias primas durante el Período de Desarrollos Regionales (PDR) e Inca. Nos centraremos en los sitios de tipo pukara y sus poblados bajos adscritos al PDR, los sitios incas y los tramos de caminos arqueológicos relevados.

Para la zona, se ha planteado que el PDR estuvo marcado por la emergencia de tradiciones locales, grupos étnicos o unidades políticas dentro de la llamada tradición santamariana y la aparición de un tipo especial de asentamiento, los pukara. Desde el norte del valle hasta su sector medio, los asentamientos se ubicaban en forma de bolsones en el curso principal del río Calchaquí y en los valles aledaños. Entre Cachi y Molinos, los sitios 
de envergadura correspondientes al PDR muestran una integración transversal de las poblaciones de la región vinculada al acceso a territorios de importante productividad agrícola y recursos económicos disímiles y al control de vías de comunicación entre diferentes zonas (Baldini \& De Feo 2000). Para este momento, los sitios más conspicuos son los pukara, ubicados en terrenos elevados, fácilmente defendibles y con excelente visibilidad sobre su espacio circundante, superando en ocasiones los 200 $\mathrm{m}$ sobre el nivel de fondo del valle. Las investigaciones realizadas en estas quebradas altas han permitido localizar 25 asentamientos arqueológicos, entre ellos al menos diez pukara distribuidos en una superficie de 149 ha. De ellos, ocho presentan ocupaciones desde el Tardío local, algunos inclusive desde sus inicios (Fuerte Tacuil, Peña Alta, Fuerte Gualfín, Cerro La Cruz, Pueblo Viejo, El Alto, Pukara de La Angostura y Luracatao) y uno es de filiación netamente inca (Pucará de Angastaco) (fig. 3) (Villegas 2006; Cremonte \& Williams 2007).

Un rasgo interesante de remarcar es la vinculación espacial (aunque no sabemos si temporal o cultural) entre pukara y espacios agrícolas (que abarcan una superficie aproximada de 350 ha) (fig. 3). Están asociados a estructuras para el manejo del agua, donde además se registran grandes bloques con grabados de motivos abstractos, horadaciones o depresiones circulares, cochas (como en Peña Alta), motivos de líneas paralelas concéntricas tipo andenes (chacras o miniaturas de campos de cultivo) y diseños con forma de tumi, escutiformes y ancoriformes (como los de Quebrada Grande y Tacuil) (Williams et al. 2010). Datos radiocarbónicos de cuatro sitios agrícolas de la zona nos permiten plantear la continuidad en el uso de los mismos desde el Formativo hasta el Colonial Temprano, a lo que sumamos la presencia en los pukara (Gualfín y Tacuil) de motivos icónicos en el arte del Tardío-Inca, como los antropomorfos en $\mathrm{T}$ y escutiformes (Williams 2015) (fig. 4, tabla 1).

La localización de los pukara en el Calchaquí medio permitió plantear la hipótesis de que, en caso de ser contemporáneos, podrían haber estado ligados al control de la circulación de personas, recursos y objetos (Williams et al. 2005; Villegas 2011). Las geoformas sobre las que se asientan destacan en el paisaje natural por su morfología y dominan visualmente grandes extensiones, pero los poblados construidos sobre ellas son visibles únicamente al llegar a la cima (fig. 5). Esto permitió pensar que sus habitantes podrían haber tenido un elevado interés en vigilar su entorno, pero no en ser fácilmente vistos por quien circulara por el fondo de las quebradas. Así, su localización estratégica pudo haber estado vinculada al control de tránsito y la interacción entre ambientes, como lo indicaría su localización con respecto a los pasos naturales (Williams 2010; Villegas 2011) (fig. 6).

\section{El Inca en el valle Calchaquí medio}

Uno de los supuestos que goza de mayor aceptación entre los arqueólogos andinos es que la imposición de la dominación cuzqueña en el siglo xv introdujo cambios especialmente en la distribución de la población, la producción agrícola, ganadera y artesanal, y fomentó modificaciones en la forma y disposición de la cultura material. Conceptos que pertenecen al dominio de lo social e ideológico se vieron asociados en contextos nuevos que pertenecen a la dominación o a su resistencia por parte de la población indígena. La dominación inca seguramente modificó el panorama contextual de las relaciones sociales de algunas regiones anexadas, tanto a nivel espacial como de la praxis, pero desconocemos si esta situación afectó a todo el Imperio. Posiblemente la creación de un nuevo paisaje social como resultado de la conquista inca fue decisiva como una estrategia de dominación de las poblaciones locales.

El Estado Inca muestra diversidad de estrategias a lo largo de su territorio. En algunos casos, fue importante la reorganización de los espacios locales y la resignificación de los nuevos; en otros, la incorporación de nuevos significados y símbolos relacionados con el Imperio jugó un papel fundamental (Williams 2008: 63).

La presencia estatal en el Calchaquí medio se distribuye tanto en el valle troncal como en el piso de puna y disminuye en las quebradas altas. Rastrear al Estado no siempre es tarea fácil, pero empezaremos por lo más conspicuo. Se relevaron seis sitios de filiación imperial: Pucará y Tambo de Angastaco, Compuel, Tambo Gualfín, Celdas de Gualfín 1 y 2 y Amaicha II, además de los sitios agrícolas de Corralito y Mayuco.

El Pucará y Tambo de Angastaco es uno de los sitios más conocidos, localizado sobre la margen derecha del río Calchaquí, a $1.862 \mathrm{msnm}$, a la vera del Camino Inca que corre en sentido norte-sur (Ruta 40) y a otro camino que, en sentido este-oeste, se dirige hacia Gualfín y Pucará. Se ubica en un contrafuerte serrano en la confluencia del río del mismo nombre y el Calchaquí, en un punto estratégico de una de las principales vías de ingreso a las quebradas altas, y está dividido en dos 


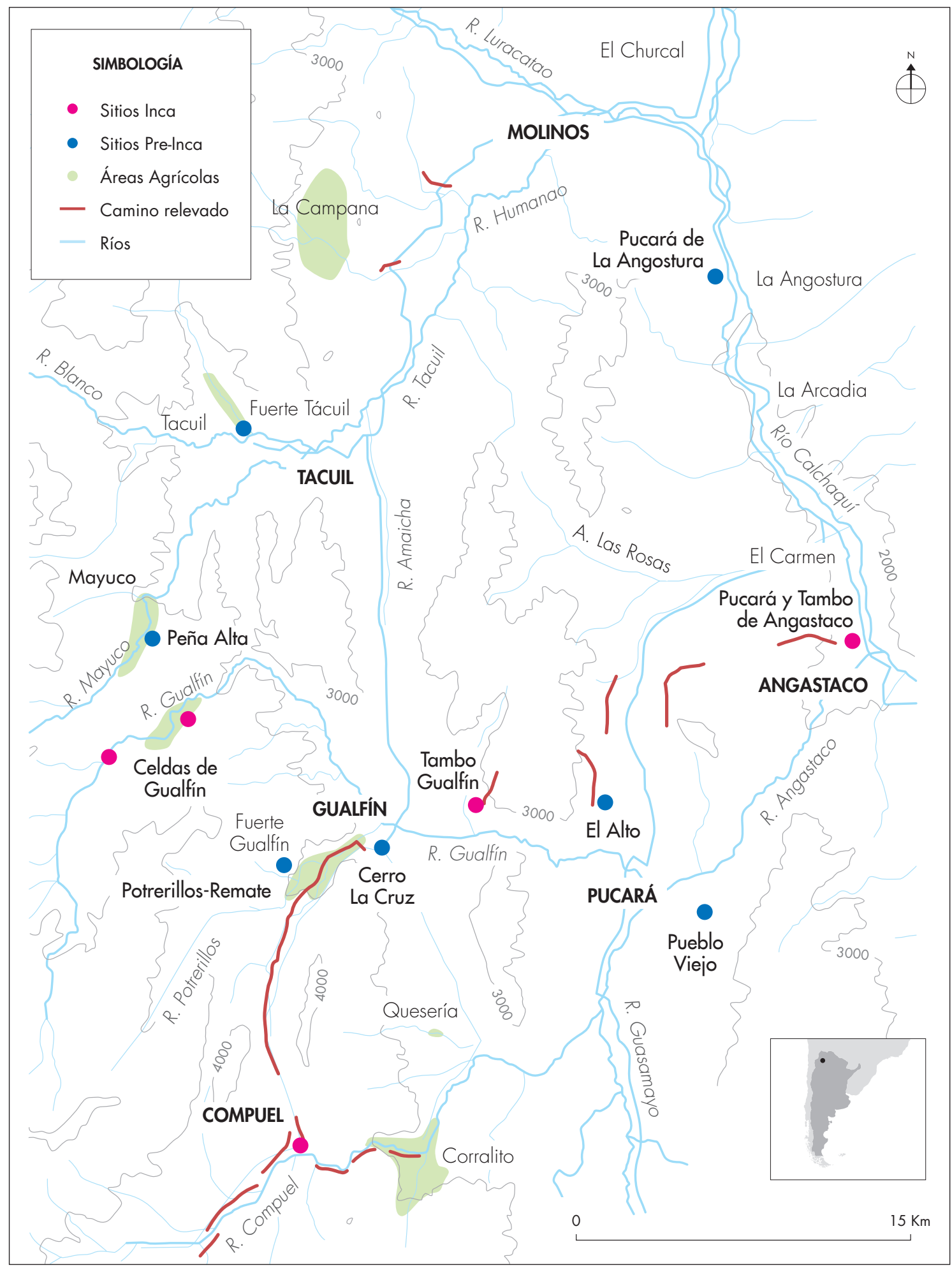

Figura 3. Sitios arqueológicos y tramos de camino relevados en el área de estudio. Figure 3. Archaeological sites and path sections highlighted in the area of study. 

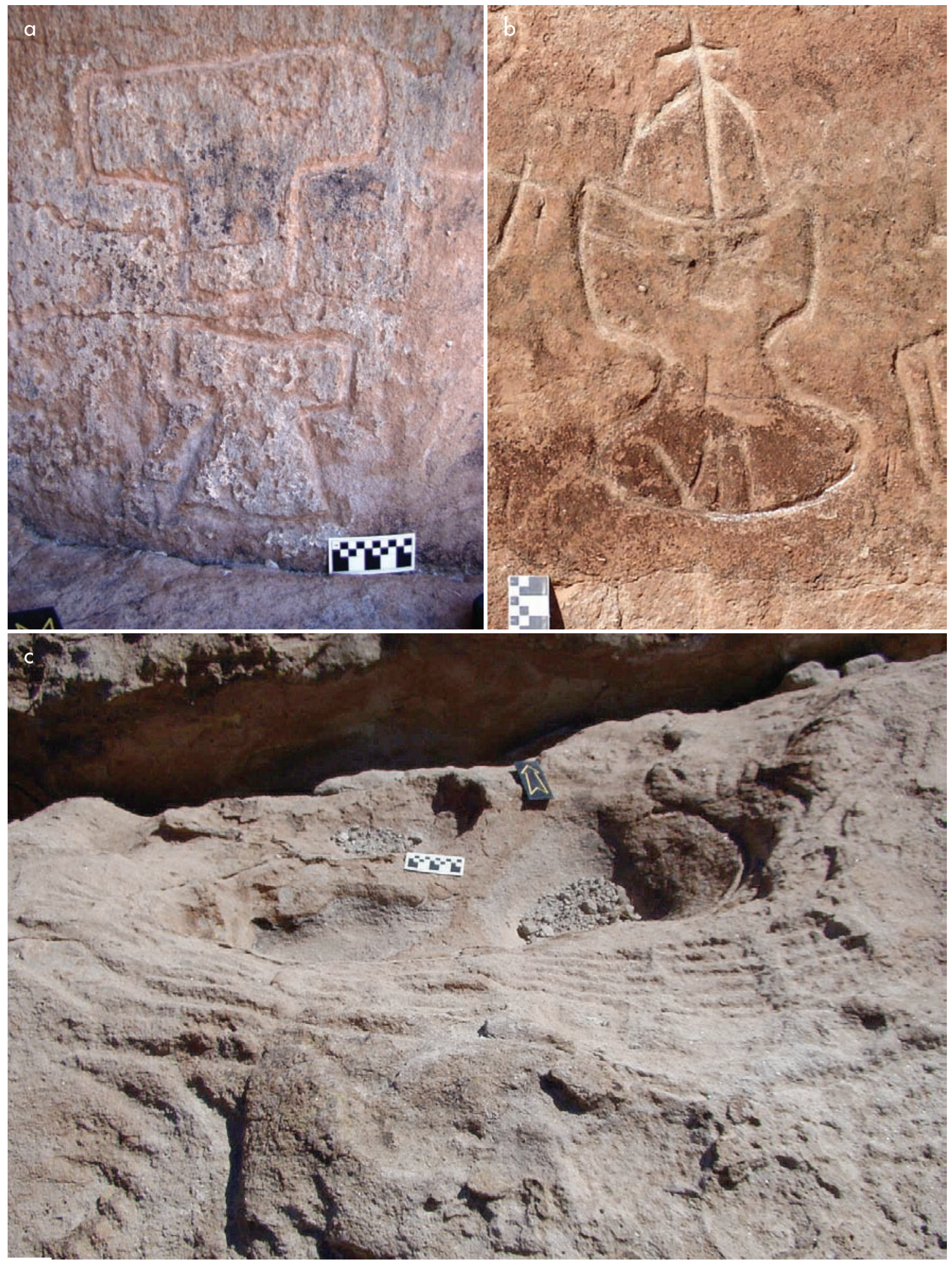

Figura 4: a) diseño en forma de tumi, Fuerte Tacuil; b) ancoriforme, Quebrada Grande; c) miniatura de campo de cultivo, Fuerte Tacuil. Figure 4: a) Tumi-shaped design, Fuerte Tacuil; b) anchor-shaped, Quebrada Grande; c) miniature of a crop field, Fuerte Tacuil. 


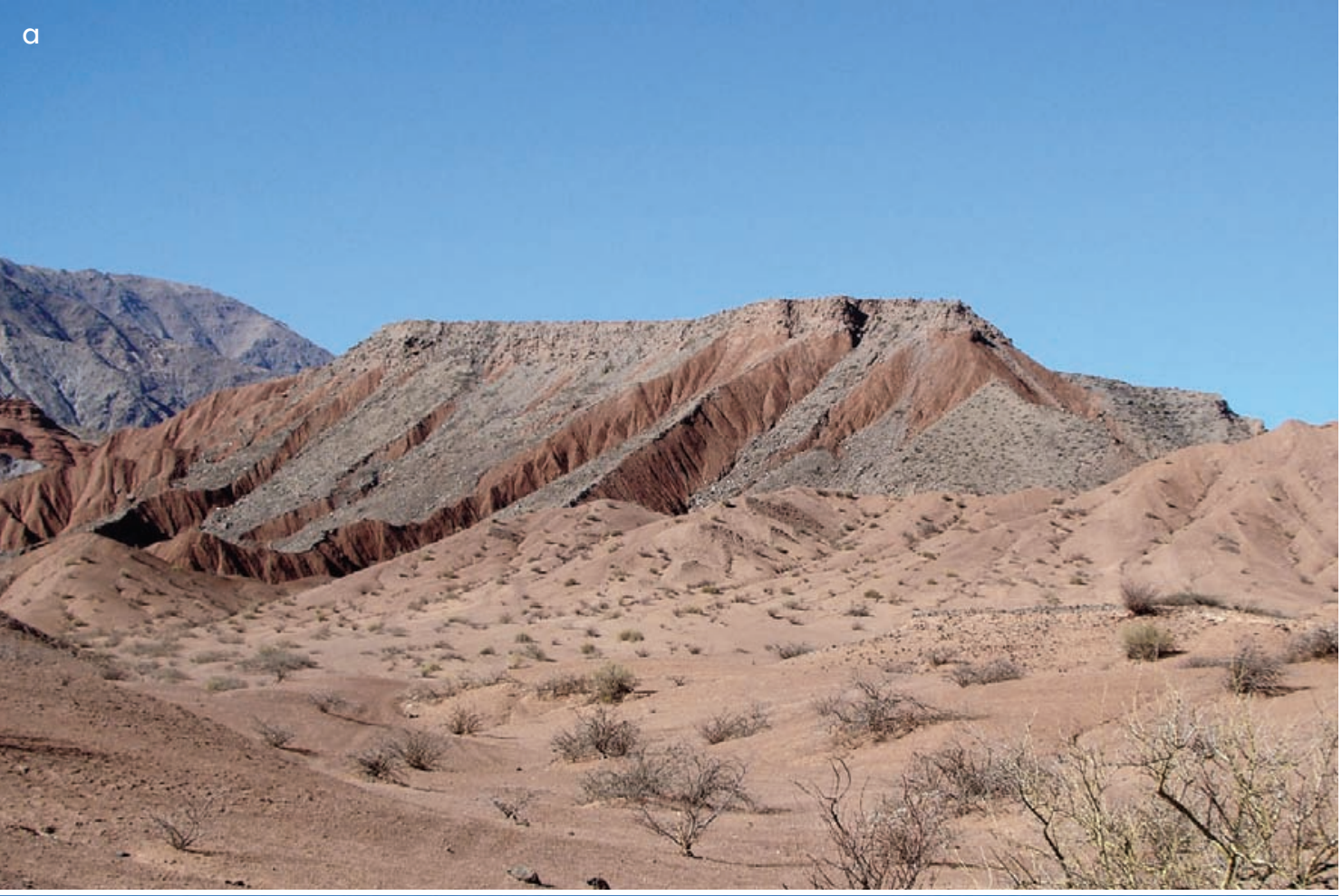

b

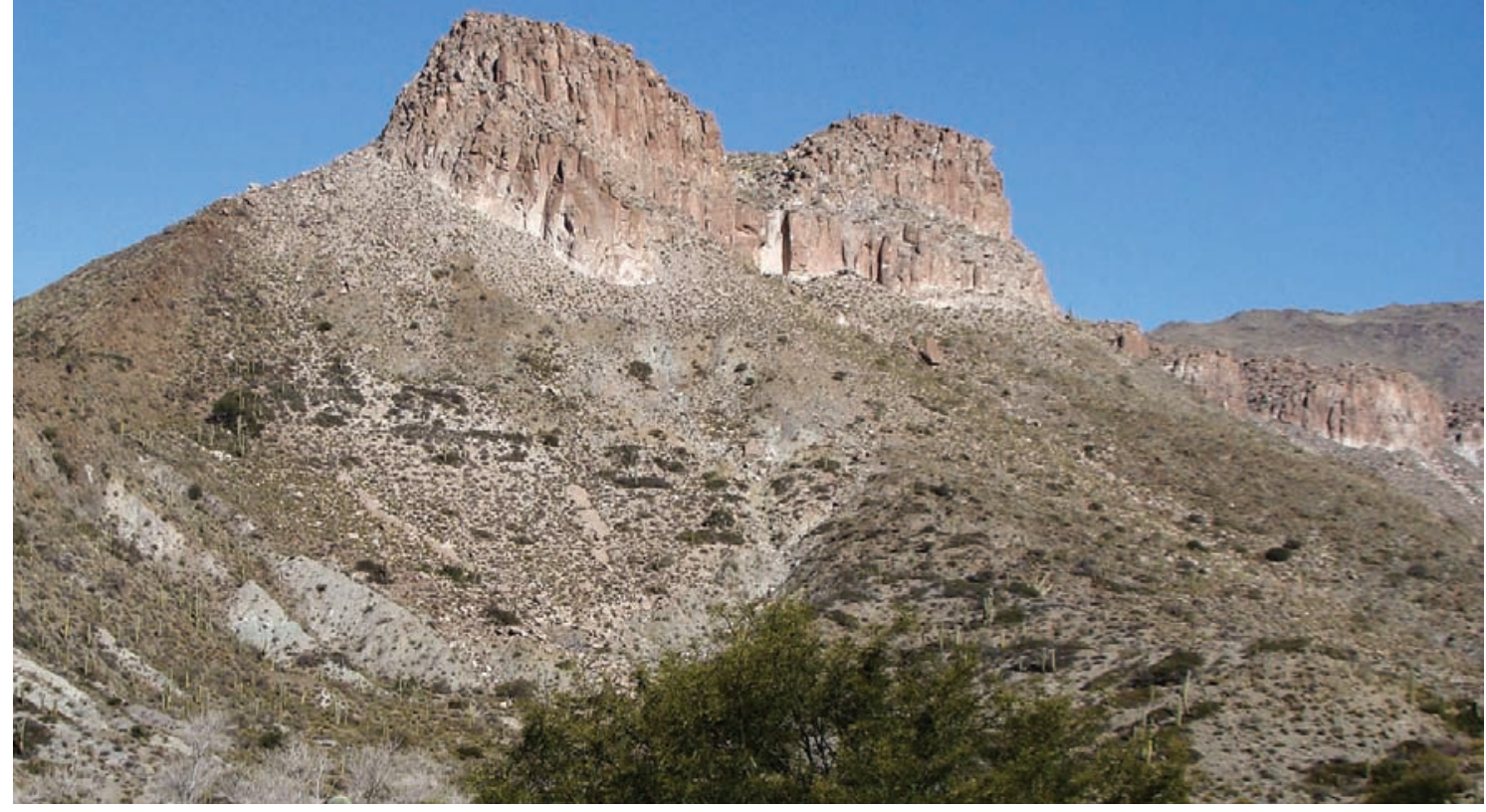

Figura 5: a) Pueblo Viejo de Pucará; b) Peña Alta de Mayuco. Figure 5: a) Pueblo Viejo de Pucará; b) Peña Alta de Mayuco. 


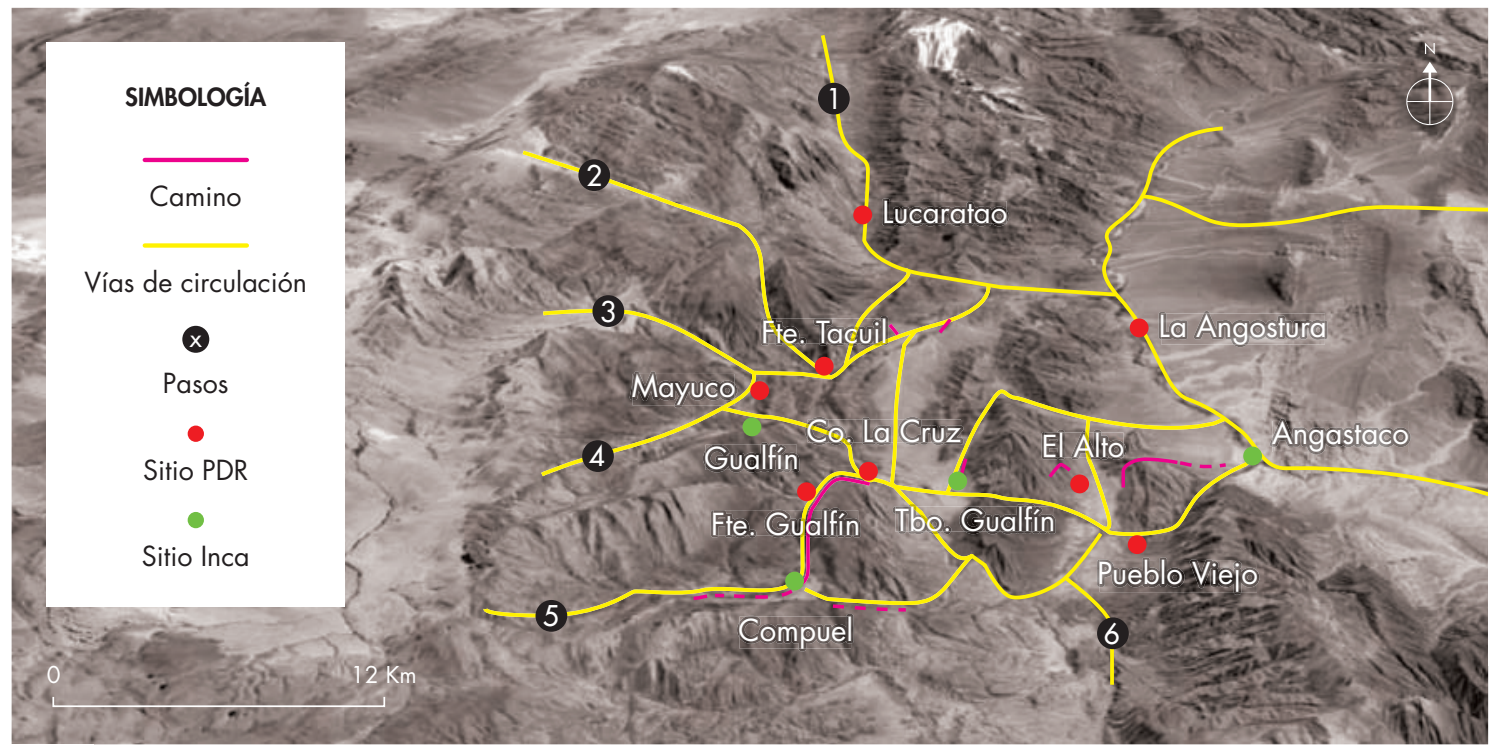

Figura 6. Vías de comunicación natural e incaicas y sitios arqueológicos relevados (imagen Google Earth). Figure 6. Natural paths, Inca Roads and archaeological sites highlighted (Google Earth image).

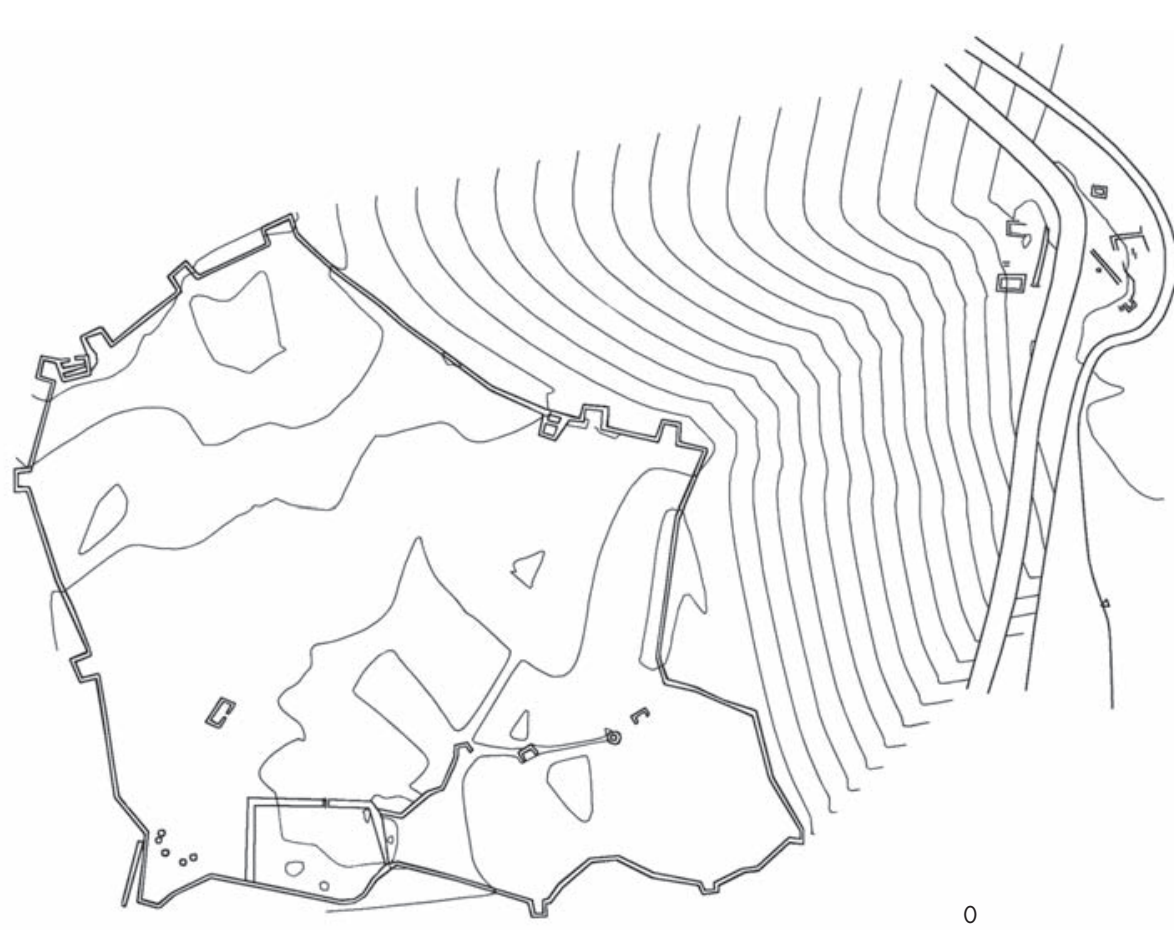

Figura 7. Plano del Pucará y Tambo de Angastaco (elaborado por M. Mariani). Figure 7. Map of the Pucará and Tambo of Angastaco (by M. Mariani). 


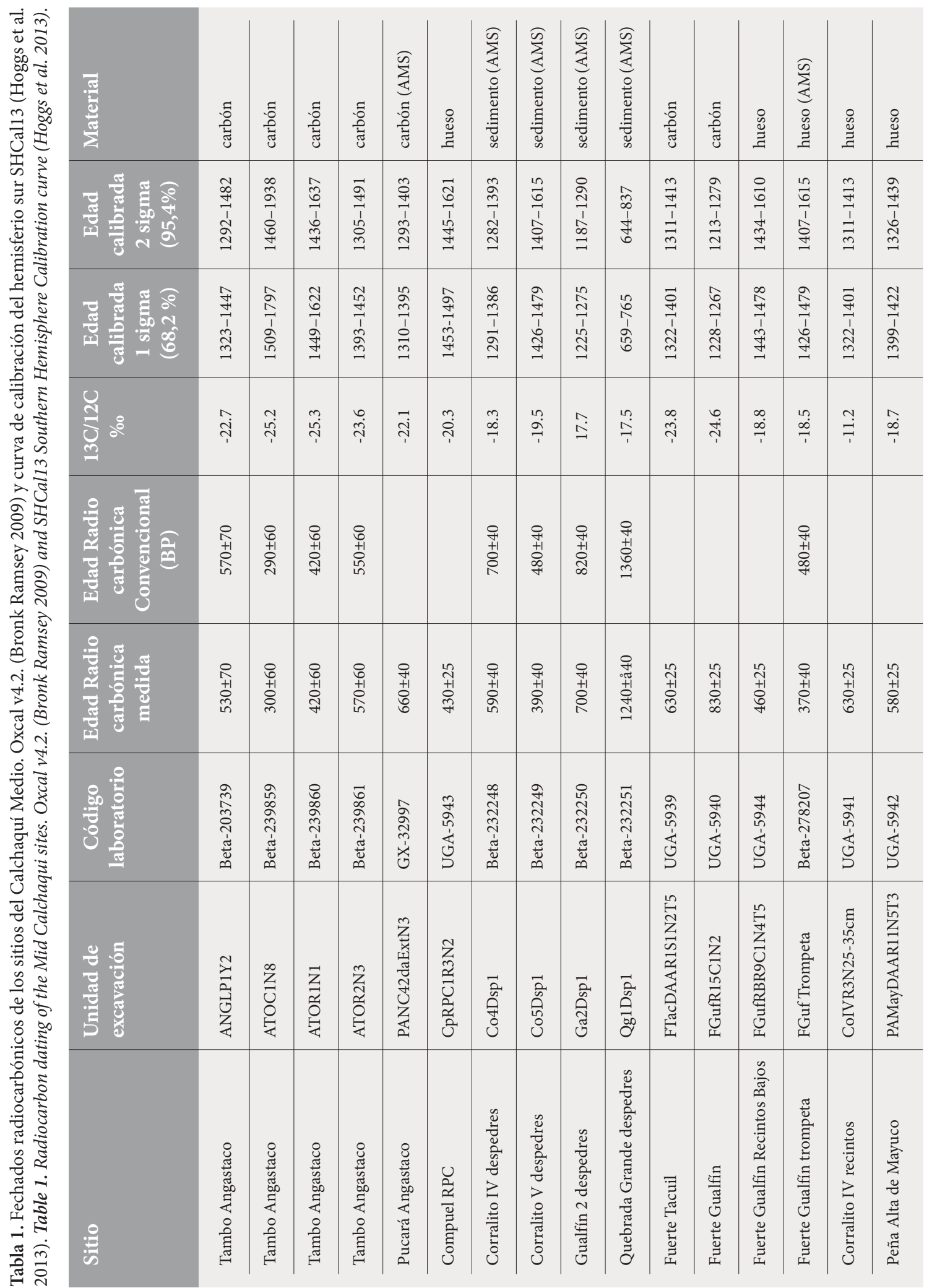


sectores con características arquitectónicas diferentes (fig. 7). El Pucará se encuentra sobre un sector amesetado del cerro que se eleva unos $31 \mathrm{~m}$ por sobre el fondo de valle $(1.950 \mathrm{msnm})$. Su rasgo más sobresaliente lo constituyen los cimientos de una muralla perimetral continua con una serie de salientes cuadrangulares, que funcionaron posiblemente como torreones. En el interior del perímetro, adosados a la muralla, se observan dos conjuntos de dos recintos cada uno, siendo los únicos restos arquitectónicos bien conservados, así como una serie de estructuras circulares (Kligmann \& Díaz País 2013; Williams \& Villegas 2013; Williams et al. 2013). Desde el Pucará se observa gran parte del valle del río Calchaquí, tanto hacia el norte como hacia el sur, así como el primer tramo de la quebrada de Angastaco, vía de comunicación hacia el oeste. La geoforma sobre la que se asienta no es imponente y sus murallas, aunque mal conservadas, son aún hoy perfectamente visibles al viajero que se aproxima desde el valle.

El sector Tambo se localiza hacia el este del pukara, en un área que actualmente ha sido modificada por la construcción de infraestructura turística. Solamente se conservan algunas estructuras rectangulares, dos de las cuales fueron excavadas (tabla 1). El material cerámico recuperado de las excavaciones integra un variado conjunto de estilos de clara filiación Inca, alcanzando más del $50 \%$ del total de fragmentos. Este sitio pudo haber constituido una defensa contra poblaciones locales hostiles, así como un recordatorio constante de la presencia y poderío inca (Williams et al. 2005, 2010; Cremonte \& Williams 2007; Chaparro 2009; Williams 2010; Williams \& Villegas 2013).

El Tambo Gualfín se ubica en un punto intermedio entre los sitios Angastaco y Compuel, a la vera del río Gualfín y en el ingreso a la quebrada que comunica Pucará con el abra de Pucarilla, por la cual se accede a tierras agrícolas (Korstanje et al. 2010; Williams et al. 2010). En la actualidad, presenta unas pocas estructuras a causa de su posterior reutilización como corral, pero está claramente asociada a un tramo de camino de tipo despejado.

Por último, en piso de puna (3.384 msnm) se ubica el sitio de Compuel (fig. 8). Presenta cinco conjuntos de tipo celda (estructuras regulares) asociadas a un RPC sobre una planicie cerca del curso actual del río homónimo (Williams 2010). El patrón celdas, con algunas variaciones, ha sido registrado en distintos puntos de Argentina, Bolivia, Chile y Ecuador, entre los 2.200 y
$4.000 \mathrm{msnm}$, siempre asociado a cursos de agua (de Hoyos \& Williams 2004, 2015; Williams \& Villegas 2013).

Este sitio se localiza en el cruce de caminos que comunican hacia el sector sur del Salar de Atacama o el Alto Loa, la puna catamarqueña y los valles mesotermales de Angastaco. Teniendo en cuenta la cantidad de estructuras con que cuenta y su localización como puerta hacia la puna donde se registran una serie de ofrendatorios y santuarios de altura, Compuel debió ser un sitio importante en el área.

Una característica registrada en este sector es que los sitios estatales se encuentran segregados de la población local, en una zona sin evidencias de grandes poblados preexistentes, a excepción de los pukara y sus pequeños semiconglomerados de base. La lógica de localización entre lo local y lo inca es diferente si consideramos que el interés de las poblaciones locales que habitaron la zona entre el 900 y el 1450 DC fue, a partir de la construcción y uso de los pukara, vigilar su entorno dada la amplia visibilidad desde los mismos, pero no en ser vistos por quien circulara por las quebradas y fondo de valle. Esta concepción se modifica con la llegada de los incas, quienes construyeron sus centros en lugares altamente visibles. Propusimos que el interés del Tawantinsuyu en este sector del valle fueron las tierras agrícolas explotadas largamente por las sociedades prehispánicas locales. Aquí, el Estado Inca habría invertido energía en maximizar las áreas agrícolas, administrando la producción de recursos y servicios desde sus centros estatales y expandiendo las líneas de cultivo a mayores alturas, posiblemente dentro de un marco de intensificación agrícola, como registramos en Corralito y Mayuco (fig. 9) (Williams et al. 2005, 2010; Williams 2008; Korstanje et al. 2010).

Si bien no se evidencia una presencia contundente de cerámica de estilo Inca en los pukara, la existencia de motivos escutiformes en el arte rupestre de la zona y en calabazas pirograbadas del contexto funerario inca de Pucarilla (Ambrosetti 1896-1899) es un importante indicio de la presencia estatal (fig. 10) (Williams et al. 2005; Williams 2010, 2015).

\section{Caminos regionales en el valle Calchaquí medio}

Vitry (2007: 347), uno de los investigadores que más ha recorrido la vialidad imperial en Argentina, señala que habría dos posibilidades de acceso al valle Calchaquí 


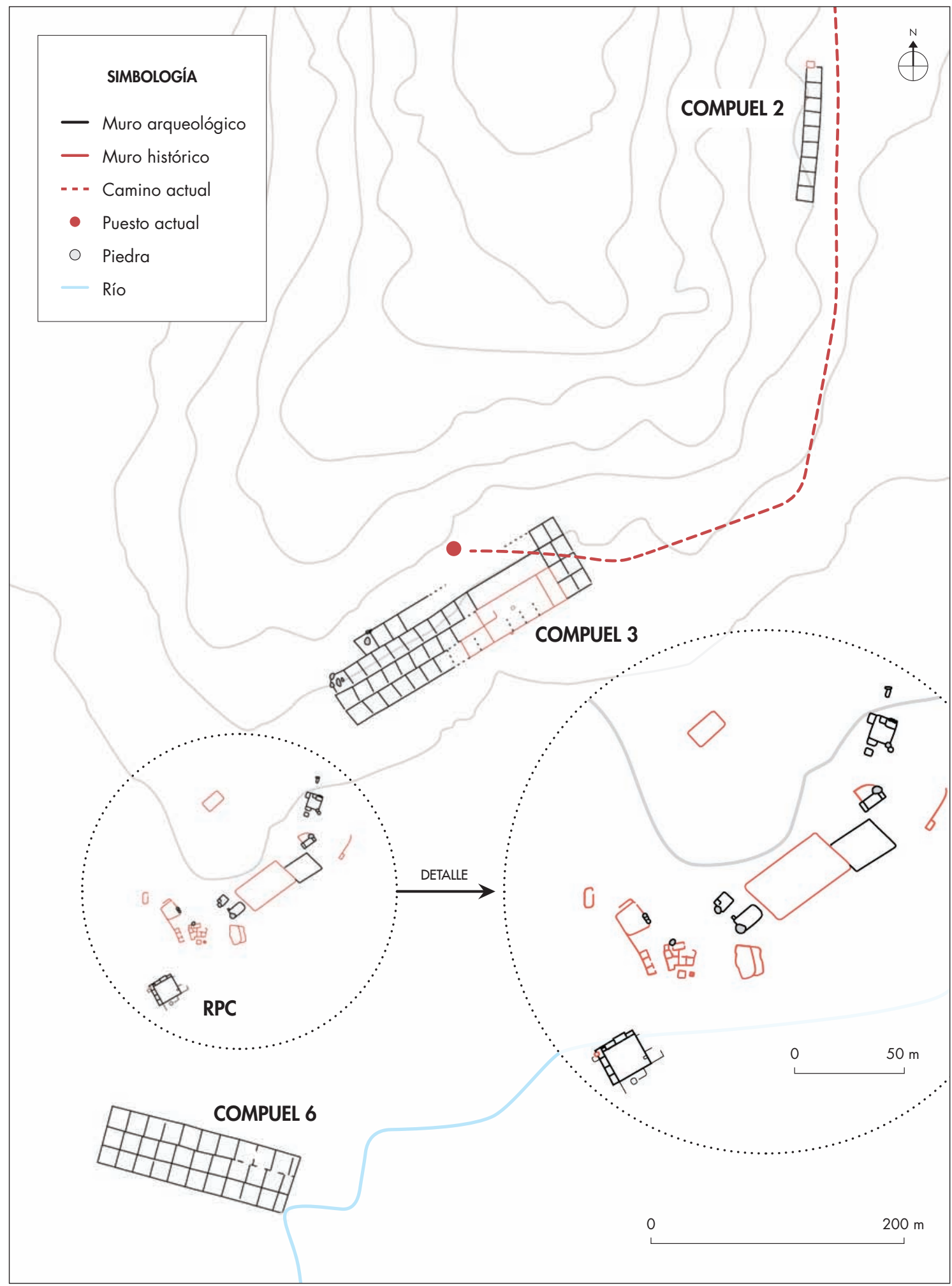

Figura 8. Plano del sitio Compuel. Figure 8. Map of the Compuel site. 

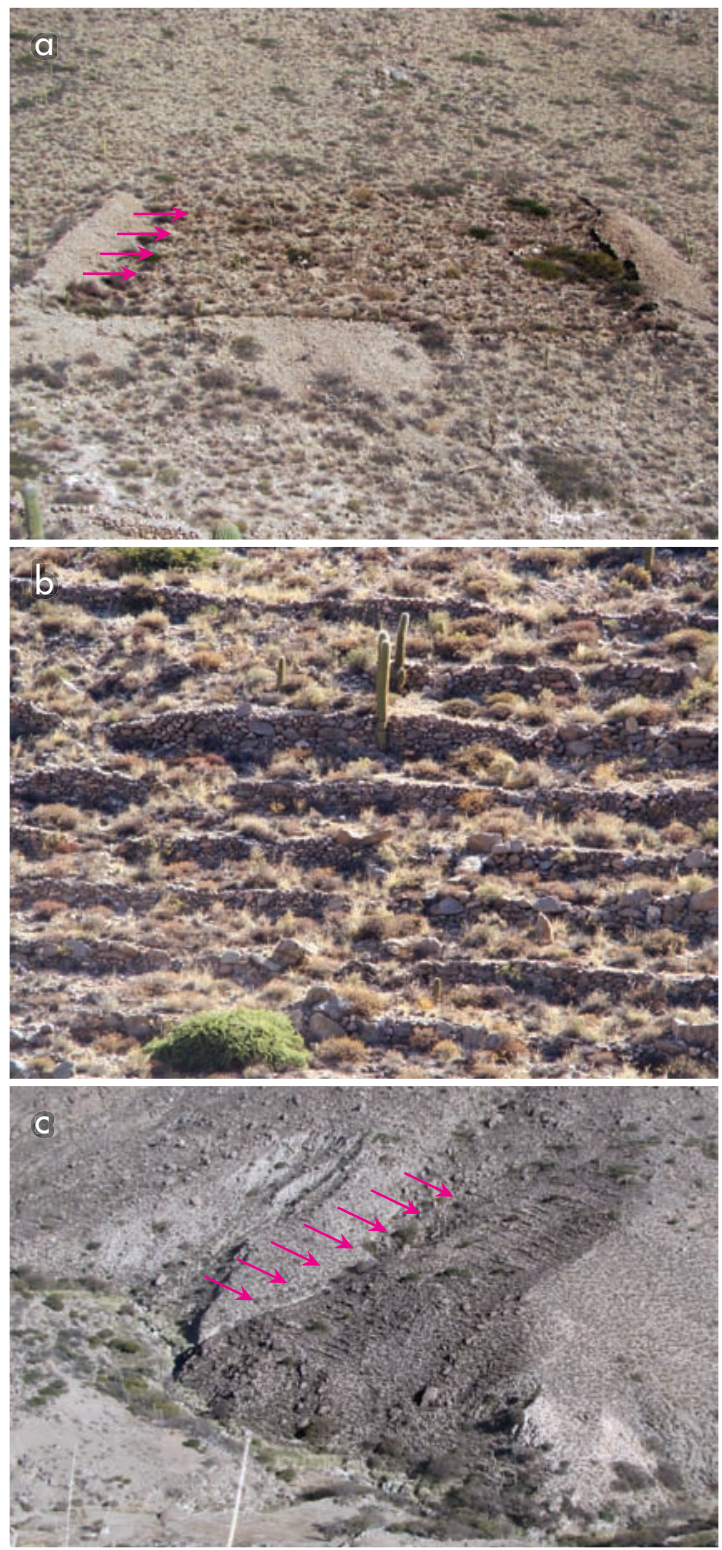

Figura 9: a) andenerías delimitadas por despedres, Corralito v; b) detalle de andenería inca, Corralito oeste; c) andenerías en Mayuco. Figure 9: a) terraced field delimited by rock debris, Corralito v; $\boldsymbol{b}$ ) detail of Inca terrace, western Corralito; $c$ ) terraced fields in Mayuco.

desde San Antonio de los Cobres, en la puna de Salta. Una sería la conocida ruta a través del Abra de Acay (5.000 msnm); la otra, una senda con componentes de filiación inca que se dirige a la sierra de Pastos Grandes, arribando a La Poma, en el extremo norte del Calchaquí. Este autor prospectó un camino con componentes incas que va desde Cachi Adentro a las
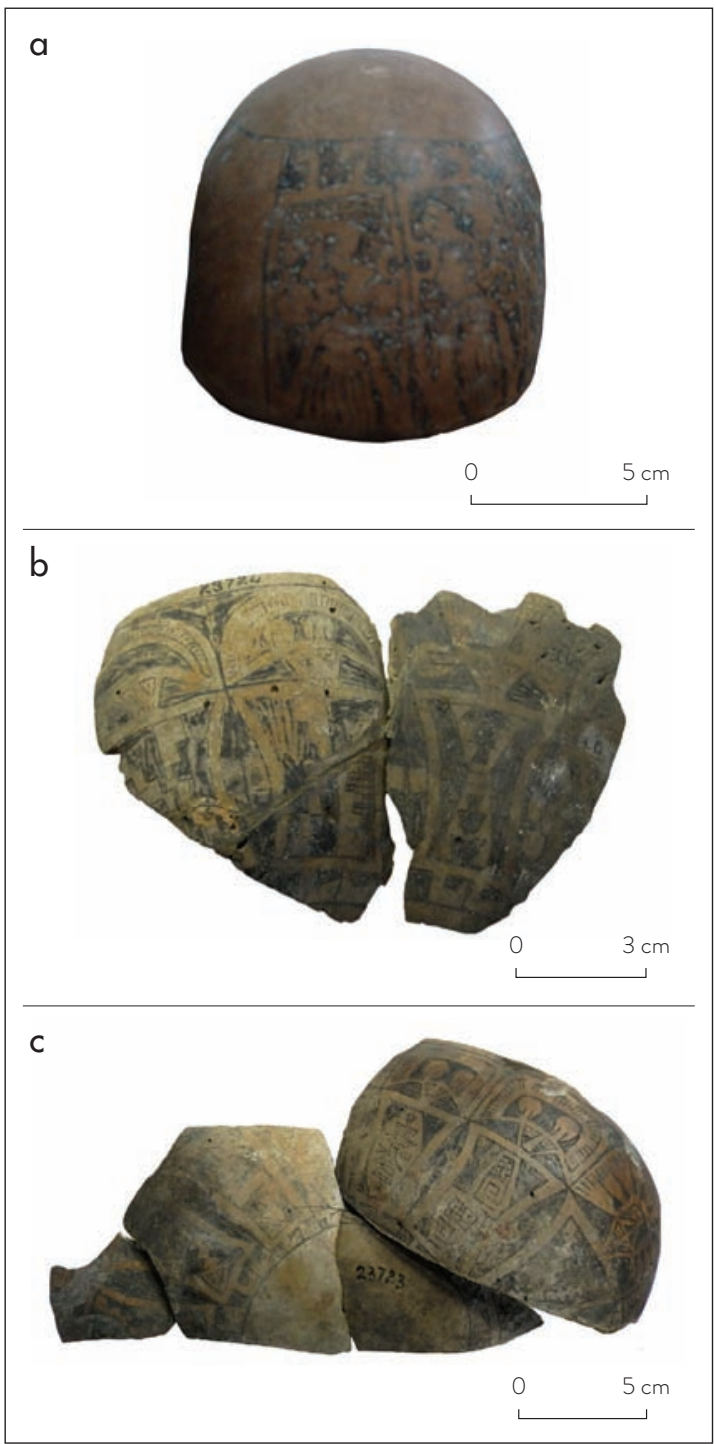

Figura 10. Calabazas pirograbadas con motivos de escutiformes: a) ejemplar de Pucará; b y c) fragmentos procedentes de Pucarilla (Ambrosetti 1902), Museo Etnográfico J. B. Ambrosetti (fotografía cortesía de C. Castellanos). Figure 10. Scutiform pyrography in gourd: $\boldsymbol{a}$ ) Pucará; $\boldsymbol{b}$ and c) fragments from Pucarilla (Ambrosetti 1902), Museo Etnográfico J. B. Ambrosetti (photo courtesy of C. Castellanos).

proximidades de Molinos, pasando por el sector occidental de La Paya, por Laguna de Brealito, y se bifurca hacia Luracatao y Colomé-Molinos (Vitry 2007: 337). En Mayuco, antes de llegar al pukara Peña Alta, se ha registrado un tramo de camino pavimentado y otro cerca de la localidad de Barrancas (3.471 msnm), 20 $\mathrm{km}$ al sur-oeste de Tacuil, en el camino hacia el cerro 
Gordo y el paraje Los Patos. Martel (2014), quien ha investigado el sector norte del volcán Galán, sostiene que habría sido paso obligado para quienes transitaban desde Antofagasta de la Sierra (puna de Catamarca) hacia otros destinos, como el valle Calchaquí central y norte o la puna centro-septentrional.

A partir de nuestras investigaciones en el área de estudio, registramos ocho tramos de vías formales factiblemente incaicas (fig. 11).

El tramo Gualfin-Compuel discurre de manera casi continua durante $17 \mathrm{~km}$, desde las inmediaciones de la actual Sala de la Finca Gualfín hasta el puesto Compuel, con dirección norte-sur. Debido a su extensión, el camino recorre diferentes tipos de terreno (entre $2.795 \mathrm{y}$ $3.530 \mathrm{msnm}$ ) predominando los faldeos montañosos y manteniendo un recorrido general a media ladera. Si bien el trazado del camino no parece haber sido modificado, en la década de 1950 fue ensanchado para permitir el paso de vehículos (Jorge Fabián 2006, comunicación personal), lo que nos impide conocer cuáles fueron sus características constructivas originales. El único tramo no reformado lo hallamos en su extremo norte, rodeando el cerro La Cruz por el sur. Allí, su ancho no supera 1 $\mathrm{m}$, es de tipo despejado y presenta algunos peldaños realizados mediante rocas dispuestas horizontalmente en los tramos de mayor pendiente. En el punto más alto del camino, en el abra donde el paisaje cambia y comienza a verse el fondo de valle de Compuel hacia el sur, ubicamos una apacheta a $3.539 \mathrm{msnm}$. Desde este mismo punto, y mirando hacia el norte, son visibles una serie de picos nevados, entre los que destacan el nevado de Cachi y el nevado de Palermo, donde se han registrado santuarios de altura. Continúa hacia el sur de Compuel, siguiendo la margen occidental del río y es posible que se dirija hacia el cerro Galán y la laguna Diamante, donde ha sido ubicado un tambo (Olivera 1991). Sostenemos que este tramo de camino estuvo posiblemente en uso en momentos incaicos, ya que conduce a Compuel, uno de los sitios estatales registrados en el área (Williams \& Villegas 2013). Si consideramos la posibilidad de que este tramo de camino haya estado conectado con aquellos vinculados al Tambo Gualfín y al que une Pucará con Angastaco, podríamos estar frente a una importante vía de comunicación entre el valle Calchaquí y el área de Antofagasta de la Sierra en la puna catamarqueña, siendo Compuel y Atacamara las dos abras más transitadas que desembocan por distintos caminos en la quebrada del río Compuel, desde donde se ingresa a los valles Calchaquíes (Olivera 1991; Williams et al. 2005; Villegas 2011; Williams 2014).

De dirección general este-oeste, el tramo CorralitoCompuel conecta el actual puesto Corralito, donde se han relevado extensas áreas agrícolas de factible filiación inca (Korstanje et al. 2010; Williams et al. 2010). Se trata de un camino con talud y muro de contención (sensu Vitry 2004: 229) que discurre por la ladera de la margen derecha del río, pero solo pudimos registrarlo por tramos, debido a la abundante vegetación y a los derrumbes. Arribando al abra que comunica con Compuel, en una parte en que el camino transita por encima de grandes bloques, registramos la presencia de al menos siete peldaños de probable origen natural que, con el continuo uso, se fueron marcando en la roca (fig. 12c).

El tramo Tambo Gualfín fue registrado inmediatamente al norte de este sitio (fig. 12b). En su primer sector, y hasta que comienza el ascenso al cerro Cuevas, es de tipo despejado (sensu Vitry 2004: 225) y de 3,87 m de ancho. Según se observó en fotografías aéreas, este tramo de camino pudo haberse unido con el AngastacoPucará (Villegas 2006; Cremonte \& Williams 2007).

Otro tramo de camino corresponde al tipo empedrado localizado en Colomé, a la vera de la ruta provincial 53, a cuyos lados parece poseer canaletas de desagüe paralelas a su trazado (fig. 12d). Es un tramo de $200 \mathrm{~m}$ de largo y $6 \mathrm{~m}$ de ancho que presenta en su punto más alto una apacheta de grandes dimensiones, de 3,19 m de alto (fig. 13a). Consideramos que el mismo pudo haber sido construido y/o remodelado en tiempos incaicos en base a sus características constructivas, siendo un camino de tipo empedrado y con talud (Cremonte \& Williams 2007; Williams \& Villegas 2013).

En Colomé, en el paraje La Campana (2.389 msnm) donde se han registrado extensas áreas agrícolas (Raffino y Cigliano 1978; Williams 2010), un tramo de camino en la quebrada que comunica ambas localidades posee un escalonado realizado con rocas dispuestas horizontalmente.

Siguiendo la ruta vehicular que une Pucará con las localidades de Jasimaná y Pampallana, registramos el tramo Pucará-Jasimaná, un camino de herradura en el que pudimos relevar tres apachetas (fig. 13c). Si bien no poseemos mayores datos, este tramo de camino podría haber estado en relación con el Angastaco-Pucará, uniendo esta última localidad con la puna salteña (Villegas 2015).

A la altura de Tacuil, y entre los dos afloramientos donde se localiza el pukara homónimo, se extendería 


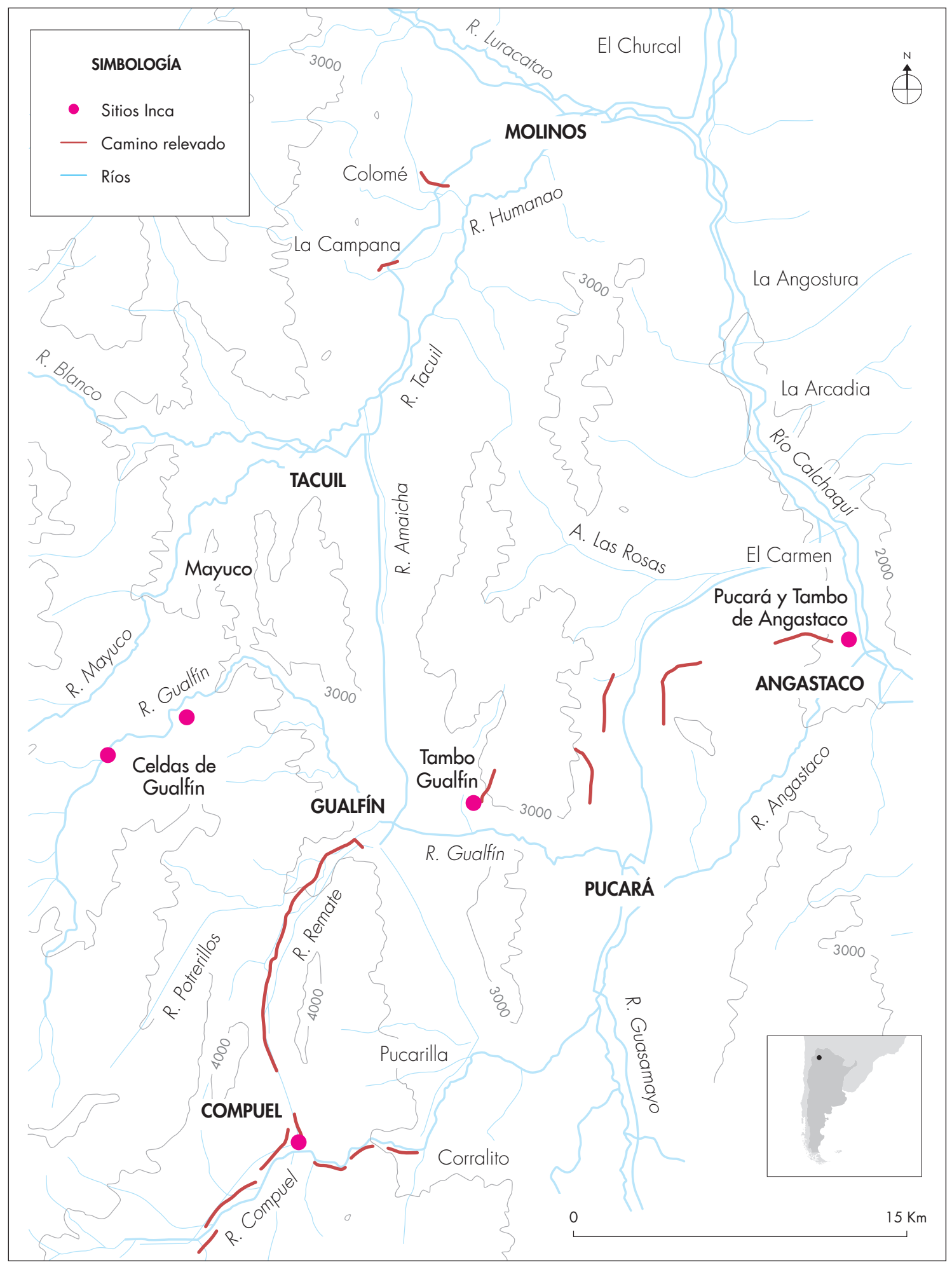

Figura 11. Caminos y sitios Incas relevados en el área de estudio. Figure 11. Inca roads and sites highlighted in the area of study. 

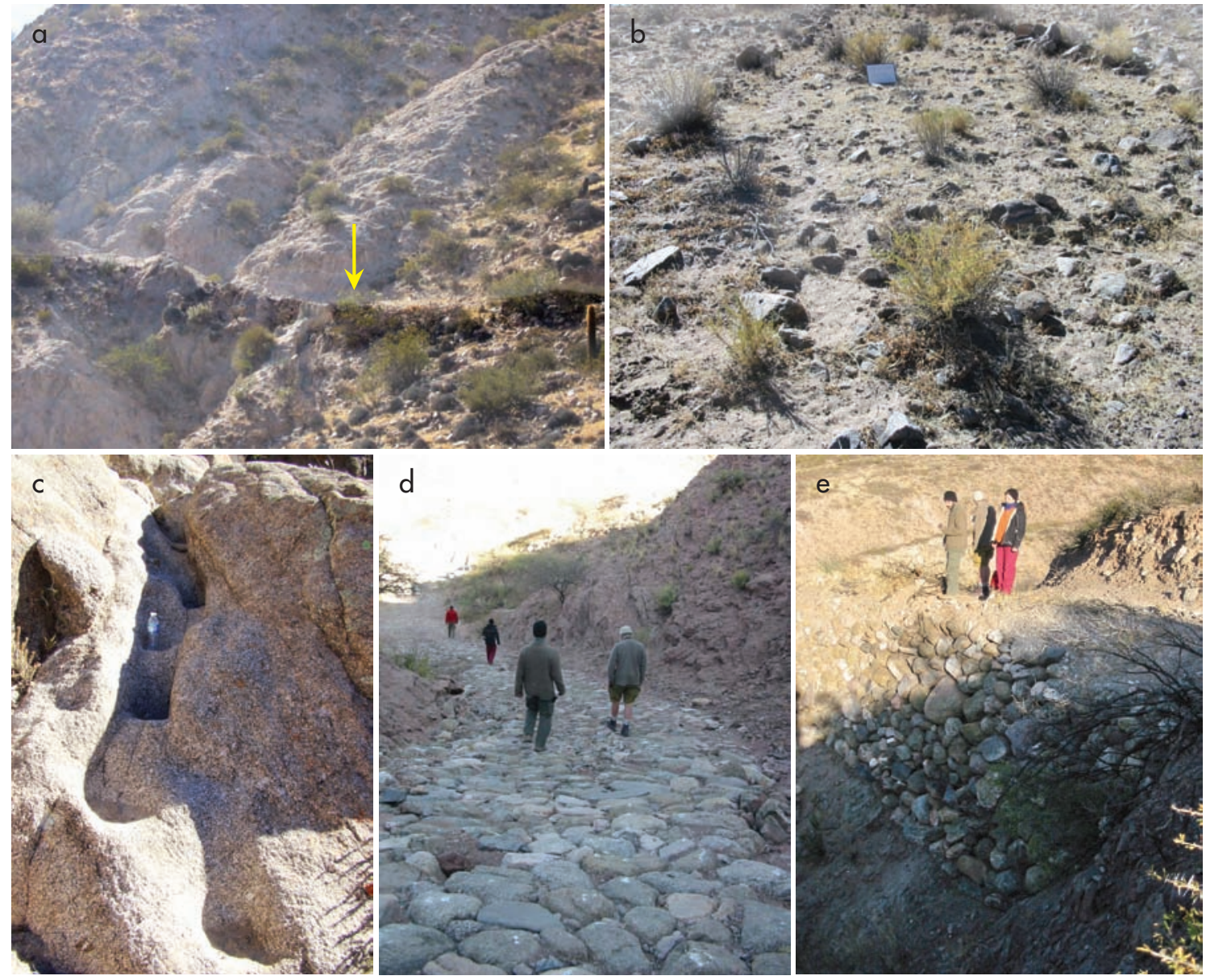

Figura 12. Caminos arqueológicos en el área de estudio: a) muro de contención en cárcava, tramo Pucará-Angastaco; b) camino de tipo despejado, Tambo Gualfin; c) escalones horadados en la roca madre, tramo Corralito-Compuel; d) camino empedrado, Colomé; e) muro de contención, Colomé. Figure 12. Archeological roads in the area under study: a) retaining wall in concavity of the rocky surface, section Pucará-Angastaco; b) clear-type road, Gualfin Tambo; c) stairs carved in bedrock, section Corralito-Compuel; d) paved road, Colomé; e) retaining wall, Colomé.

un tramo de camino que se dirige a Mayuco y de allí al abra del cerro Gordo, paso a la puna (Viveros 2014 com. pers.). Al sudoeste de Tacuil, por la quebrada de Palan Palan, se llega al abra Vizconzillo, en donde se erigen dos apachetas a $3.137 \mathrm{msnm}$. Desde allí se accede al pukara de Peña Alta por el este, y siguiendo esta ruta a través de Barrancas se alcanza la cuenca del río Los Patos en la región puneña.

Por su parte, el tramo más extenso registrado en el área es Angastaco-Pucará (de al menos $12 \mathrm{~km}$ ), el que parte de la base del cerro Cuevas y se extiende hasta unos 4,7 km al sudoeste del Pucará de Angastaco. En su primera parte es un camino de tipo herradura con muros de contención en los sectores donde la ladera es de mayor gradiente. Frente al cerro Cuevas, en la margen opuesta del valle, el camino continúa por otros $8 \mathrm{~km}$ con dirección oeste-este, ascendiendo al cerro Bayo y descendiendo luego hacia Angastaco. En esta segunda parte el camino es de tipo despejado, con tramos excavados en la ladera y presencia de muros de contención en los sectores donde lo cruzan cárcavas, en que su ancho varía entre 1 y 2 m (fig. 12a). A lo largo de su recorrido registramos cuatro apachetas, tres de las cuales son muy pequeñas; la más importante se ubica en el punto más elevado del camino (2.638 $\mathrm{msnm}$ ) $y$ es de 5,76 por $6,78 \mathrm{~m}$ (fig. 13c). Luego el camino comienza a bajar por el lecho de un curso de agua con dirección este-oeste, siendo aquí de tipo despejado, con 

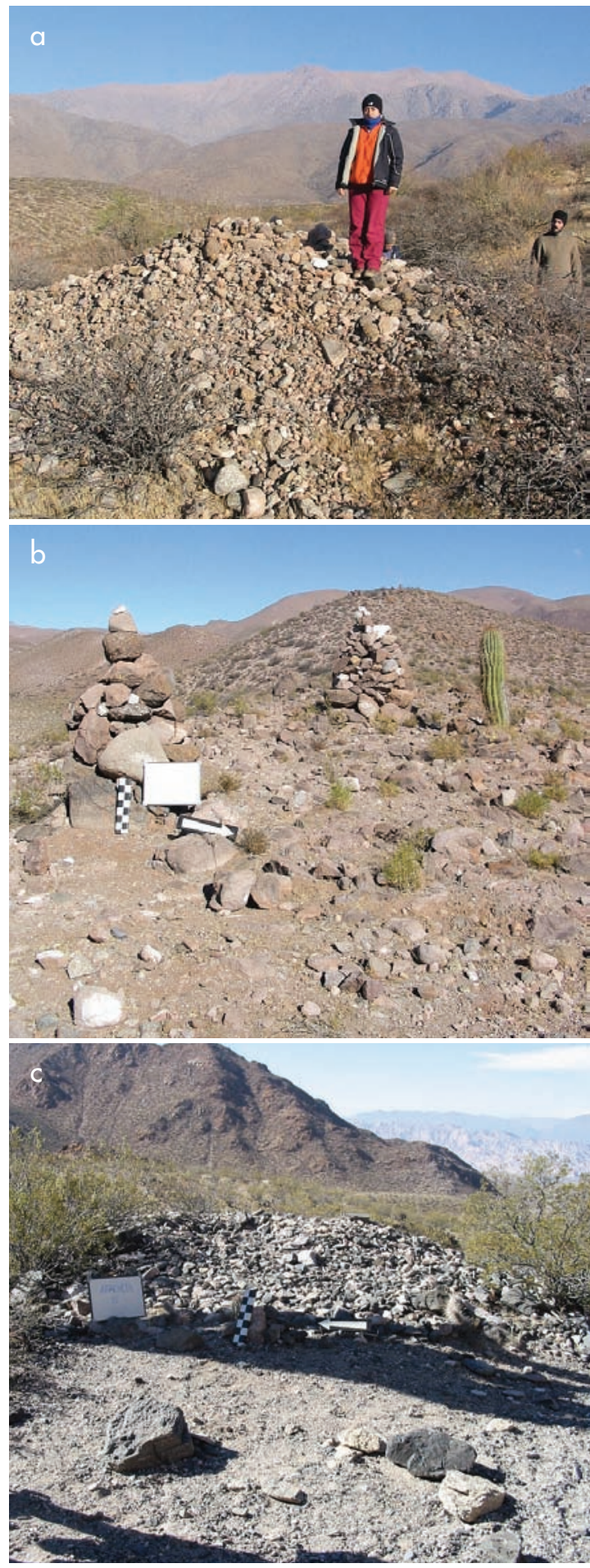

Figura 13. Apachetas asociadas a los caminos: a) tramo PucaráAngastaco; b) tramo Pucará-Jasimaná; c) tramo Colomé. Figure 13. Roadside apachetas: a) section Pucará-Angastaco; b) section Pucará-Jasimaná; c) section Colomé. un ancho de aproximadamente 2,33 m y presencia de dos estructuras circulares o plataformas pequeñas que pudieron corresponder a lugares de descanso (Villegas 2006; Cremonte \& Williams 2007).

\section{CONCLUSIONES}

El camino fue el mayor demarcador del territorio incaico y un recordatorio constante del dominio estatal. En el sector medio del valle Calchaquí, en la provincia de Salta, se han relevado varios tramos de caminería imperial que corresponden a los tipos empedrado con muros de contención (Colomé), despejado (Tambo Gualfín) y directamente excavados en la ladera (AngastacoPucará). En algunos casos, se evidencian escalones para salvar pendientes más pronunciadas (Gualfín-Compuel y Corralito-Compuel) y en otros se utiliza y "recicla" elementos naturales con talud y muro de contención (Angastaco-Pucará, Gualfín, Corralito).

Estos tramos conectan sitios estatales con clara arquitectura imperial construidos en lugares relativamente alejados de los asentamientos locales y áreas productivas, como el Pucará y Tambo de Angastaco sobre una de las terrazas del río Calchaquí, de fácil visibilidad y acceso; Tambo de Gualfín en fondo de valle en el río Gualfín y de los sitios tipo Celdas de Gualfín y Compuel en el piso de puna.

La presencia estatal en estos sectores del valle conllevó no solo la colonización de nuevos espacios sino la apropiación de lugares con historia previa como los pukara. La concentración de pukara en el área, emplazados sobre geoformas elevadas y con excelente visibilidad del espacio circundate, localizados sobre las vías de circulación naturales, nos sugiere un interés en controlar/defender ciertos espacios o territorios y sus pasos hacia la puna por parte de las poblaciones del PDR (fig. 13). Si bien se ha sostenido que, dada la multiplicidad de rutas en los Andes, los pukara no habrían necesariamente defendido y/o controlado las vías de comunicación (Nielsen 2007), consideramos que las limitaciones topográficas nos permiten sostener la hipótesis de control para este sector.

Williams (2010) señala que estos asentamientos tuvieron un papel relevante en el PDR, en el sentido de haber constituido geosímbolos o marcas en el paisaje durante momentos posteriores, cobrando protagonismo nuevamente en la Colonia temprana, en los sucesivos levantamientos indígenas. 


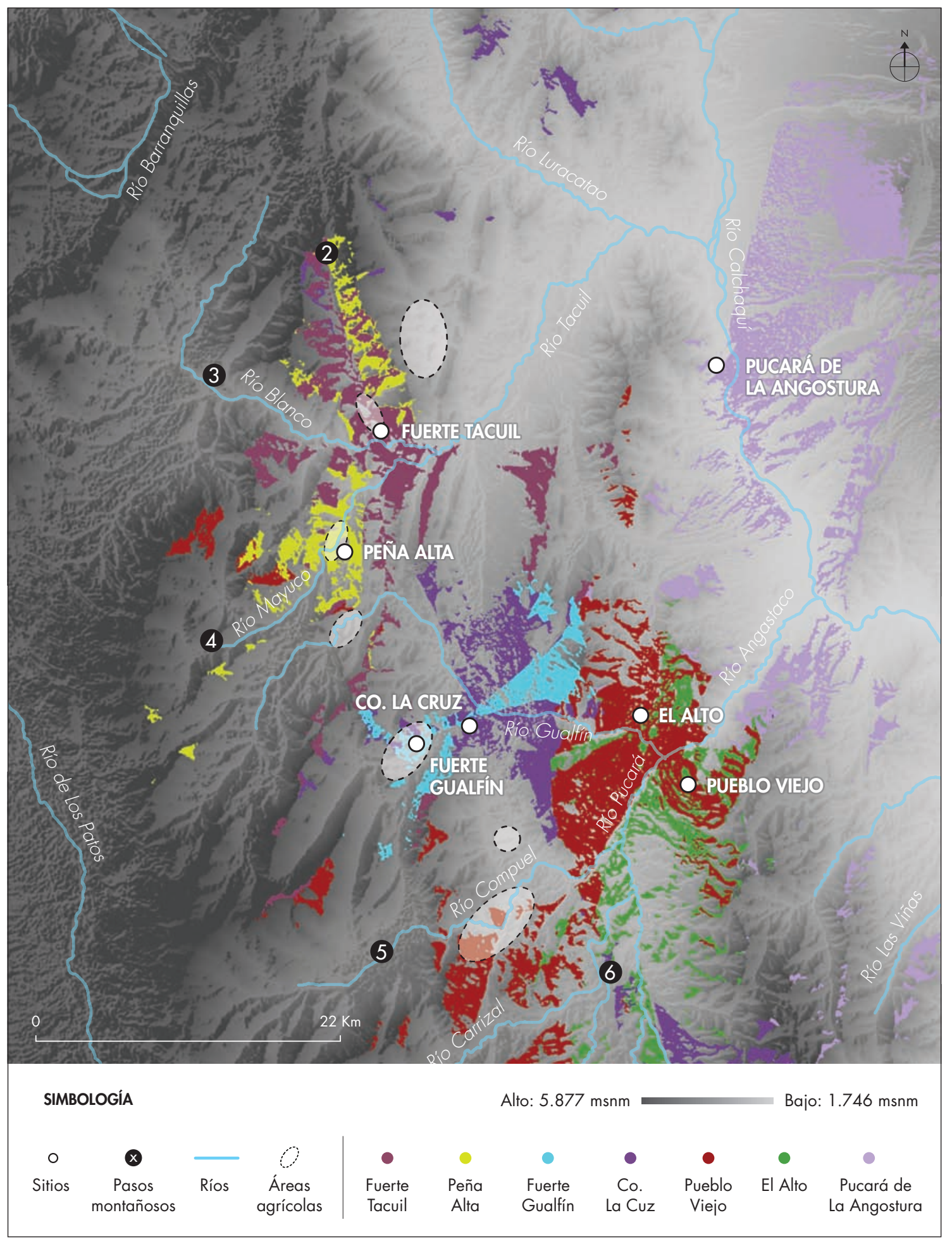

Figura 14. Mapa del área de estudio para el PDR, con el área visible de cada pukara en relación con los pasos a puna (el Pucará de Angastaco fue incluido como referencia). Figure 14. Map of the area of study for the RDP, including visible areas from each pukara in relation to the mountain passes to the Puna (Pucará de Angastaco included for reference). 


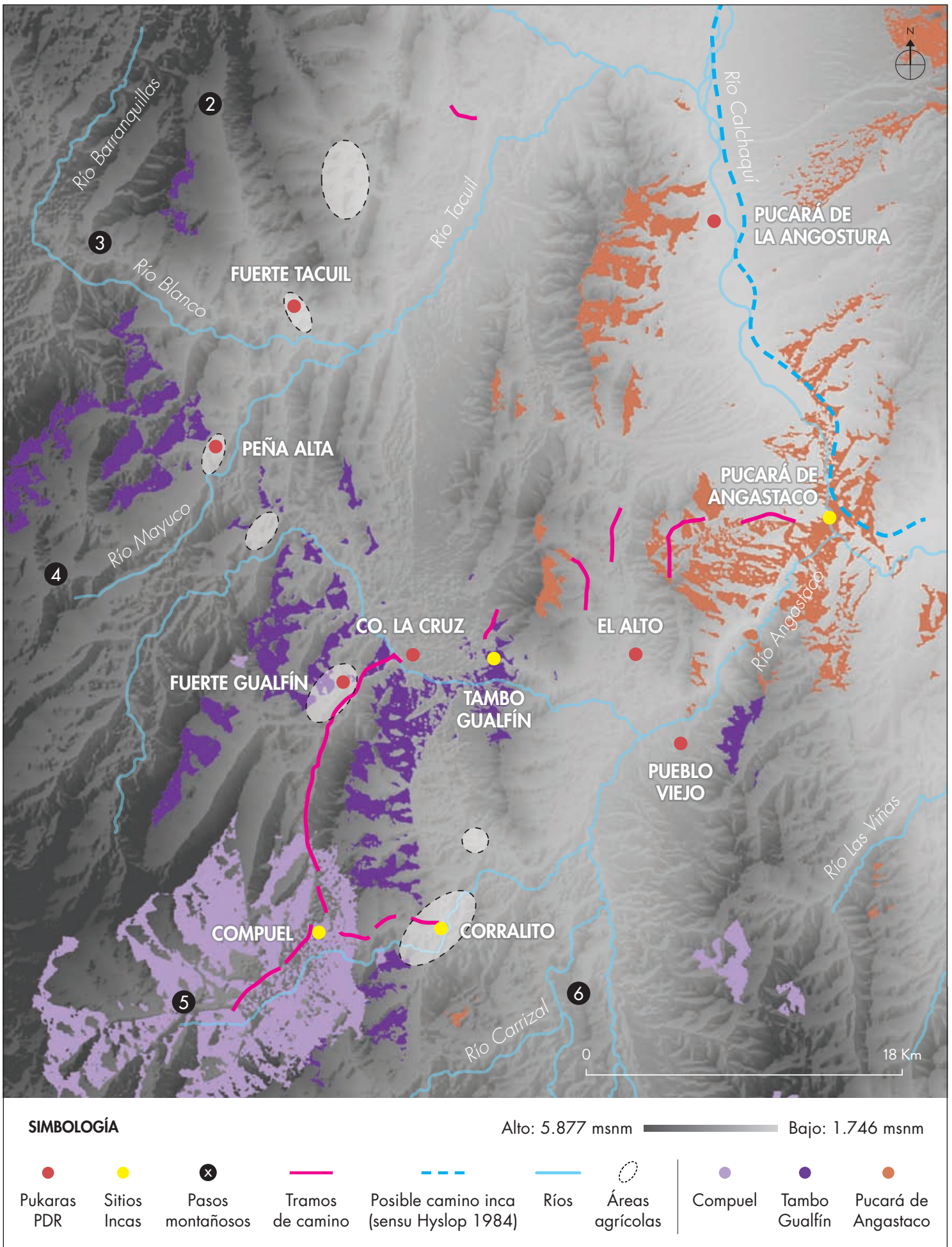

Figura 15. Mapa del área de estudio donde se muestran los caminos y sitios incas con el área visible desde cada uno en relación con los pasos a puna. Figure 15. Map of the area of study, indicating visible areas from each road and Inca site in relation to the mountain passes to the Puna. 
Aún no podemos asegurar si los pukara responden a una situación de conflicto local o interregional previo a la conquista inca, como espacios de refugio y de resistencia de las poblaciones locales. Por su parte, los asentamientos estatales en este sector del valle son notablemente visibles en el paisaje, representando posiblemente "un cambio en la estructura del paisaje local” (Williams 2010: 17). La reconfiguración del paisaje durante la colonización inca se dio a partir de la instalación de sitios estatales sobre el fondo de valle troncal y el piso de puna, a la manera de marcadores en el paisaje.

Sobre la base de la localización de los sitios y de los tramos de Camino Inca relevados, observamos que, frente a la multiplicidad de posibilidades de circulación registradas para el PDR en el área, durante el momento Inca la misma parece haberse decantado preferentemente por el sector sur, comunicando Angastaco con Compuel por un paso que habría conducido hacia la región de Antofagasta de la Sierra (fig. 14) (Olivera 1991; Villegas 2011, 2015; Martel 2014). Esto no implica que las otras rutas no hayan continuado en uso, sino que parece haber sido esta la escogida para asuntos "oficiales". ${ }^{1}$ En relación con este último punto, para el Período Inca se registra en la zona un franco predominio del uso, como materia prima, de obsidiana de la fuente Ona (puna catamarqueña), mientras que para el PDR se registran también obsidianas procedentes del salar del Hombre Muerto y laguna Cavi (Chaparro 2009: 535). Esto podría haber implicado no necesariamente una regulación estatal de las fuentes, sino tal vez una reducción en la libre circulación en el área que habría quedado reflejada en el aprovisionamiento de las obsidianas para este período.

En este punto, nos planteamos nuevas interrogantes sobre el papel de los caminos estatales y locales durante la dominación Inca en la zona: ¿cómo pudo haber influido esto en los circuitos y las redes de interacción local y en la generación de nuevos espacios y sujetos involucrados en el manejo de tales circuitos? En las quebradas altas, la presencia de materias primas y objetos procedentes de otros lugares (como la obsidiana, los metales y calabazas, así como estilos cerámicos regionales como el negro pulido del Tardío, Pacajes y Yavi) en asentamientos y espacios anexados a la política inca nos permite sugerir que estos objetos podrían estar dotados de un prestigio similar al de los bienes estatales. Así, la cerámica negra pulida típica del Tardío local amplía su circulación durante el momento Inca, hallándose en asentamientos del Calchaquí norte como La Paya, en el sector medio como El Churcal, en las quebradas altas como Tacuil y al sur de Angastaco como en Payogastilla, así como en la Quebrada del Toro (Baldini \& Sprovieri 2009).

En este escenario, en los asentamientos tardíos de las quebradas altas los estilos locales continúan manufacturándose y circulando durante momentos incaicos. Por ejemplo, en Tacuil la caracterización microscópica de la cerámica permitió reconocer una litología relativamente uniforme y similar a la litología local. Los materiales cerámicos se corresponden con los estilos locales definidos para el Tardío (fragmentos Santamariano en sus variedades bicolor y tricolor, negro sobre rojo y toscos peinados), aunque también se hallaron escasos fragmentos Belén, negros pulidos tardíos (sensu Baldini \& Sprovieri 2009) y unos pulidos cuyas características permitieron definirlos como un grupo separado. La cerámica de Gualfín también corresponde a los estilos locales definidos para el Tardío en el valle (Santamariano negro sobre crema, negro sobre rojo y tricolor, ordinarios y pulidos) y aquí se destacan algunos fragmentos que por su decoración se asemejan al estilo Valle Arriba sensu Serrano (1976 [1958]). El hallazgo de cerámica de estilo Valle Arriba en un área tan septentrional a la de su área de dispersión (Cafayate), y su presencia en un contexto de entierro múltiple del Tardío-Inca en la zona de Payogastilla, al sur de Angastaco, dio a lugar al planteo de la hipótesis de que el estilo Valle Arriba podría estar representando una Fase Inca para el sur del valle Calchaquí (Vasvári 2014: 83).

La presencia en el área de una importante ruta transversal de comunicación con la puna explicaría la localización tanto del Pucará de Angastaco como de Compuel (fig. 15). La localización de un sitio de las características del Pucará de Angastaco en la entrada de esa ruta pudo obedecer tanto a razones logísticas (movimiento de bienes y tropas, entre otros) como administrativas, funcionando asimismo como un demarcador espacial y tal vez como una demostración del poder del estado para las poblaciones locales. Así, la apropiación del territorio del valle Calchaquí medio dentro del Imperio Inca habría resultado en un paisaje local "incaizado" por medio de una serie de estrategias o marcas en el paisaje que constituyeron no solo una inclusión política y económica del área, sino una apropiación simbólica de la misma (Bonnemaison 2005). Aquí, estas marcas incluyeron desde la instalación de nuevos asentamientos hasta la construcción de caminos, incorporación de un estilo imperial característico en la 
cultura material y la apropiación de espacios productivos por medio del arte.

RECONOCIMIENTOS A las familias Dávalos y Bonner por la hospitalidad en las campañas. A Mariano Mariani, Soledad Gheggi, Elena Díaz País, Lía Arcehaga, Guadalupe Romero, Carlos Calzadilla, Pedro Salminci†, Roberto Pappalardo, Patricia Camaño y Mabel Mamaní por su trabajo en el campo.

\section{NOTAS}

${ }^{1}$ Fuera de nuestra área de estudio en la cuenca del Salar de Pastos Grandes, se localiza el sitio Abra de Minas y la Cueva Inca Viejo, importantes sitios estatales (López et al. 2015) a los que se habría accedido por las cabeceras del río Tacuil.

\section{REFERENCIAS}

Ambrosetti, J. B., 1896-1899. Notas de arqueología calchaquí. Boletín del Instituto Geográfico Argentino XVII-Xx.

Baldini, L. \& C. DE Feo, 2000. Hacia un modelo de ocupación del valle Calchaquí central (Salta) durante los Desarrollos Regionales. Relaciones de la Sociedad Argentina de Antropología xxv: 75-98.

BAldini, L. \& M. Sprovieri, 2009. Vasijas negras pulidas: una variedad de la cerámica tardía del valle Calchaquí. Estudios Atacameños 38: 21-38.

BárCenA, J. R., 2005. Avances 2002-2003 sobre el conocimiento arqueológico y etnohistórico de la dominación inka en el centro oeste argentino, extremo austral oriental del Tawantinsuyu. Xama 15-18: 119-149.

Benedetti, A., 2005. El ferrocarril Huaytiquina, entre el progreso y el fracaso. Aproximaciones desde la geografía histórica del territorio de los Andes. Escuela de Historia 4: 123-165. Salta.

Berenguer, J., 2001. Couvre-chefs, identité et interaction dans le désert chilien, avant et après la chute de Tiahuanaco. Dossiers de l'Archeologie 262: 66-77.

Bertrand, A., 1885. Memoria sobre las cordilleras del desierto de Atacama i rejiones limítrofes. Santiago: Imprenta Nacional.

Bonnemaison, J., 1992. Le territoire enchanté. Croyances et territorialités en Mélanésie. Géographie et culture 3: 72-88.

Bonnemaison, J., 2005. Culture and space. Londres: Tauris.

BRonk RAMSEY, C., 2009. Bayesian analysis of radiocarbon dates. Radiocarbon 51 (1): 337-360.

Castillo, A., 1978. Geología y petrología de la zona Tacuil, Cerro Blanco, Dpto. Molinos, Provincia de Salta. Seminario de Geología, Universidad Nacional de Salta.

Chaparro, M. G., 2009. Ms. Los artefactos y los recursos líticos de las sociedades pre-estatales y estatales del Noroeste Argentino: sur de la quebrada de Humahuaca, valle del río Potrero, quebradas de Gualfín y Tolombón y bolsón de Andalgalá. Tesis para optar al grado de Doctor, Facultad de Filosofía y Letras, Universidad de Buenos Aires, Argentina.

Cremonte, M. B. \& V. Williams, 2007. La construcción social del paisaje durante la dominación inka en el Noroeste Argentino. En Procesos sociales prehispánicos en el sur andino. La vivienda, la comunidad y el territorio, A. Nielsen, M. Rivolta, V. Seldes, M. Vázquez \& P. Mercolli, Comps., pp. 207-236. Córdoba: Brujas.

De Hoyos, M. \& V. williams, 2004. Arquitectura inka para propósitos especiales. Revista Pacarina. En prensa.

De Hoyos, M. \& V. williams, 2015. Abran kancha... una variante de recinto perimetral compuesto en el Noroeste Argentino. Estudios Atacameños. En evaluación.

FÁbrega, P. \& C. PARCERo, 2007. Proposals for an archaeological analysis of pathways and movement. Archaeologia e Calcolatori 18: 121-140.

García Sanjuán, L.; S. Metcalfe-Wood, T. Rivera Jiménez \& D. Wheatley, 2006. Análisis de pautas de visibilidad en la distribución de monumentos megalíticos de sierra Morena occidental. En La aplicación del sig a la arqueología del paisaje, I. Grau, Ed., pp. 181-200. Alicante: Universidad de Alicante.

García, S.; D. Rolandi, M. López \& P. Valeri, 2002. Viajes comerciales de intercambio en el Departamento de Antofagasta de la Sierra, puna meridional argentina: pasado y presente. Redes 2 (5): 1-24. Barcelona.

Hogg, A.; Q. Hua, P. Blacwell, M. Niu, C. Buck, T. Guilderson, T. Heaton, J. Palmer, P. Reimer, R. Reimer, C. Turney \& S. Zimmerman, 2013. SHCal13 Southern Hemisphere Calibration, 0-50,000 Years cal BP. Radiocarbon 55 (4): 1889-1903. Hyslop, J., 1984. The Inka Road system. Orlando: Academic Press. INGOLD, T., 1993. The temporality of the landscape. World Archaeology 25 (2): 152-174.

Kligmann, D. \& E. Díaz País, 2013. Mirando lo invisible. Primeros análisis físico-químicos de los sedimentos de los sitios Tolombón y Angastaco (Provincia de Salta). En Al borde del imperio. Paisajes sociales en áreas periféricas del Qollasuyu, V. Williams y B. Cremonte, Eds., pp. 253-272. Buenos Aires: Publicaciones de la Sociedad Argentina de Antropología.

Korstanje, A.; P. Cuenya \& V. Williams, 2010. Taming the control of chronology in ancient agricultural structures. Non traditional data sets. Journal of Archaeological Science 37: 343-349.

Larrouy, A., 1923. Documentos del Archivo de Indias para la historia del Tucumán, tomo I. Buenos Aires: Rosso y Cía. Impresores.

Levillier, R., 1926. Nueva crónica de la conquista del Tucumán. Madrid: Sucesores de Rivadeneyra.

López, G. \& F. Coloca, 2015. El sitio Abra de Minas: nuevos aportes para la caracterización de las ocupaciones Tardío/ Inca en las tierras altas del NOA. Bulletin de l'Institut Francais d'Etudes Andines 44 (1): 141-149.

López, G.; F. Coloca, S. Araya, J. P. Orsi \& S. Seguí, 2015. El sitio cueva Inca Viejo, salar de Ratones, puna de Salta: evidencia arqueológica y procesos de interacción macrorregional. Relaciones de la Sociedad Argentina de Antropología XL (1): 45-71. 
Lorandi, A. M. \& R. Boixados, 1987-1988. Etnohistoria de los valles Calchaquíes en los siglos xvi y xvir. Runa xvII-XviII: 266-419.

Lorandi, A. M. \& M. De hoyos, 1995. Complementariedad económica en los valles Calchaquíes y del Cajón, siglos XVXvir. En Colonización agrícola y ganadera en América siglos XVI-XVIII. Su impacto en la población aborigen, L. Escobari de Querejazu, Comp., pp. 385-414. Quito: Abya Yala.

Malpass, M., 1993. Provincial Inca. Archaeological and ethnohistorical assessment of the impact of the Inca State. Iowa: University of Iowa Press.

Martel, A., 2014. Aguas Calientes. Evidencias directas de tráfico caravanero entre la puna meridional y el valle Calchaquí. Estudios Sociales del NOA 13: 103-124.

Martínez, J. L., 1998. Pueblos del chañar y el algarrobo. Los atacamas del siglo XVII. Santiago: DIBAM-Facultad de Filosofía y Humanidades, Universidad de Chile.

Mata de López, S., 2000. Tierra y poder en Salta. El Noroeste Argentino en vísperas de la independencia. España: Diputación de Sevilla.

Moralejo, R., 2011. Los inkas al sur del valle de Hualfín: organización del espacio desde una perspectiva paisajística. Tesis para optar al grado de Doctor, Facultad de Ciencias Naturales y Museo, Universidad Nacional de La Plata, Argentina.

Nielsen, A., 2007. Bajo el hechizo de los emblemas: políticas corporativas y tráfico interregional en los Andes Circumpuneños. En Producción y circulación prehispánicas de bienes en el sur Andino, A. Nielsen, M. C. Rivolta, V. Seldes, M. Vázquez \& P. Mercolli, Comps., pp. 393-411. Córdoba: Brujas.

Olivera, D., 1991. La ocupación inka en la puna meridional argentina. Comechingonia 9: 33-72.

Philippi, R., 1860. Viage al desierto de Atacama, hecho de orden del gobierno de Chile en el verano 1853-1854. Halle en Sajonia: Librería Eduardo Anton.

Presta, A. M., 2013. Aportes multidisciplinarios al estudio de los colectivos étnicos surandinos. Reflexiones sobre QaraqaraCharka tres años después. La Paz: Instituto Francés de Estudios Andinos-Plural.

Raffestin, C., 1986. Ecogenès e territoriale et territorialité. En Espaces, jeuxetenjeux, F. Auriac \& R. Brunet, Eds., pp. 173185. París: Fayard.

Raffino, R., 1981. Los Inkas del Kollasuyu. La Plata: Ramos Americana.

Raffino, R. \& E. Cigliano, 1978. Nota sobre una nueva instalación agrícola en el N. O. Argentino. Revista del Instituto de Antropología 6: 93-104.

Serrano, A., 1976 [1958]. Manual de la cerámica indígena. Córdoba: Assandri.

SProvieri, M., 2013. El mundo en movimiento: circulación de bienes, recursos e ideas en el valle Calchaquí, Salta (Noroeste Argentino). Una visión desde La Paya. Oxford: ArchaeopressBritish Archaeological Reports.

Strube Erdmann, L., 1963. Vialidad imperial de los incas. Instituto de Estudios Americanistas. Serie Histórica xxxıII. Córdoba:
Facultad de Filosofía y Humanidades, Universidad Nacional de Córdoba.

TARragó, M., 2000. Chacras y pukara. Desarrollos sociales tardíos. En Nueva historia argentina, volumen I, M. Tarragó, Comp., pp. 257-300. Buenos Aires: Sudamericana.

Tномаs, J., 2001. Archaeologies of place and landscape. En Archaeological theory today, I. Hodder, Ed., pp. 165-186. Cambridge: Polity.

TorreblanCA, H. DE, 1999 [1696]. Relación histórica del Calchaquí. Versión paleográfica de Teresa Piossek. Buenos Aires: Archivo General de La Nación.

VASvari, v., 2014. Evidencias de ocupación incaica en Payogastilla. Sector sur del valle Calchaquí. Tesis para optar al grado de Antropóloga, Facultad de Humanidades, Universidad Nacional de Salta, Argentina.

Villegas, M. P., 2006. Teledetección arqueológica en el valle Calchaquí medio (Salta, Argentina). Tesis para optar al grado de Antropóloga, Departamento de Ciencias Antropológicas, Facultad de Filosofía y Letras, Universidad de Buenos Aires.

Villegas, M. P., 2011. Paisajes en movimiento. El uso del espacio durante los Períodos de Desarrollos Regionales e Inca en el valle Calchaquí medio (Salta, Argentina). Estudios Sociales del NOA 11: 63-82.

Villegas, M. P., 2015. Del valle a la puna: articulación social y económica entre los poblados prehispánicos Tardíos y los asentamientos inkas en la quebrada de Angastaco (valle Calchaquí medio, Salta). Tesis para optar al grado de Doctora, Facultad de Filosofía y Letras, Universidad de Buenos Aires.

VITRY, C., 2000. Aportes para el estudio de Caminos Incaicos. Tramo Morohuasi-Incahuasi. Salta: Gofica.

Vitry, C., 2004. Camino de los Diaguitas y del Inga en Escoipe. Intersecciones entre la historia y la arqueología. Escuela de Historia 1 (3): 259-271. Salta.

Vitry, C., 2007. Caminos rituales y montañas sagradas. Estudio de la vialidad inka en el nevado de Chañi, Argentina. Boletín del Museo Chileno de Arte Precolombino 12 (2): 69-84.

Von TschUdi, J., 1967 [1858]. Viaje por las cordilleras de los Andes de Sudamérica, de Córdoba a Cobija. Boletín de la Academia Nacional de Ciencias xuv: 1-38. Córdoba.

Williams, V., 2008. Espacios conquistados y símbolos materiales del Imperio Inca en el noroeste de Argentina. En Lenguajes visuales de los Incas, P. González \& T. L. Bray, Eds., pp. 47-70. Oxford: BAR-Archaeolopress.

WiLliams, V., 2010. El uso del espacio a nivel estatal. En El hábitat prehispánico. Arqueología de la arquitectura y de la construcción del espacio organizado, M. E. Albeck, M. C. Scattolin \& M. A. Korstanje, Eds., pp. 77-114. Jujuy: EDIUnJu.

Williams, V., 2014. Sociedades prehispánicas Tardías en el Noroeste Argentino. Una aproximación a trayectorias históricas en el Valle Calchaquí durante el Tawantinsuyu. En Ocupación Inka y dinámicas regionales en los Andes (siglos XV-XVII), C. Rivera Casanovas (ed.), pp. 123-154. La Paz: IfEA-Plural.

Williams, V., 2015. Formaciones sociales en el Noroeste Argentino. Variabilidad prehispánica en el surandino durante el Período 
de Desarrollos Regionales y el Estado Inca. Huacaypata 4 (9): 62-76.

Williams, V.; M. P. Villegas; M. S. Gheggi \& M. G. Chaparro, 2005. Hospitalidad e intercambio en los valles mesotermales del Noroeste Argentino. Boletín de Arqueología de la PUCP 9: 335-373.

Williams, V.; M. A. Korstanje, P. Cuenya \& M. P. Villegas, 2010. La dimensión social de la producción agrícola en un sector del Valle Calchaquí medio. En Arqueología de la agricultura, A. Korstanje \& M. Quesada, Eds., pp. 178-201. Tucumán: Magna.
Williams, V.; M. P. Villegas \& L. Arechaga, 2013. Paisajes de Tolombón. ¿De poblado tardío a capital de un wamani? En Al Borde del Imperio. Paisajes sociales, materialidad y memoria en áreas periféricas del Noroeste Argentino, V. Williams \& M. B. Cremonte, Eds., pp. 143-176. Buenos Aires: Publicaciones de la Sociedad Argentina de Antropología.

Williams, V. \& M. P. Villegas, 2013. Colonización estatal en las cuencas de Angastaco-Molinos (Salta, Argentina). En Al Borde del Imperio. Paisajes sociales, materialidad y memoria en áreas periféricas del Noroeste Argentino, V. Williams \& M. B. Cremonte, Eds., pp. 221-252. Buenos Aires: Publicaciones de la Sociedad Argentina de Antropología. 